\title{
INCIDENCIA DE LAS VARIABLES CLIMÁTICAS EN LOS RENDIMIENTOS DE LOS CULTIVOS TRANSITORIOS EN LA PROVINCIA DEL ALTO MAGDALENA 1992-2013
}

MAIRA ALEXANDRA RODRÍGUEZ TOVAR

Director: Olga Marina García Norato Ph.D

Proyecto de Trabajo de Grado para Optar al

Título de Magister en Ciencias Económicas

\section{UNIVERSIDAD SANTO TOMÁS \\ DIVISIÓN DE CIENCIAS ECONÓMICAS Y ADMINISTRATIVAS \\ MAESTRÍA EN CIENCIAS ECONÓMICAS \\ BOGOTÁ}

2015 


\section{Tabla de contenido}

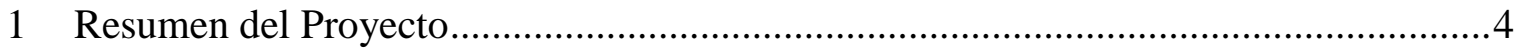

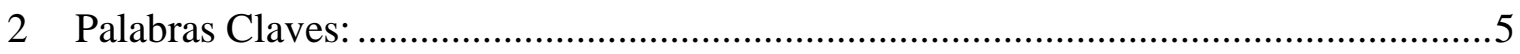

3 Planteamiento del Problema ................................................................................

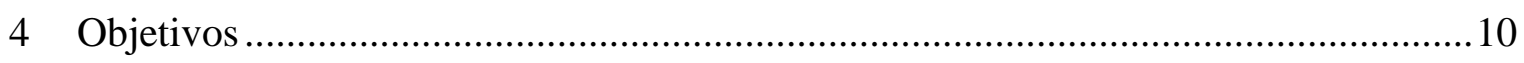

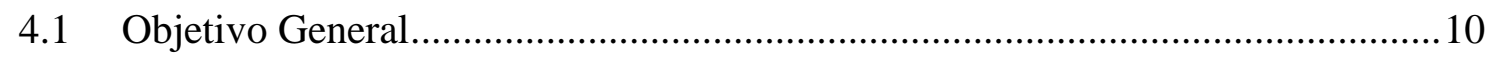

4.2 Objetivo Específicos ............................................................................ 10

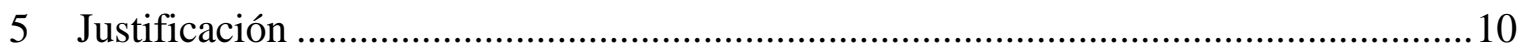

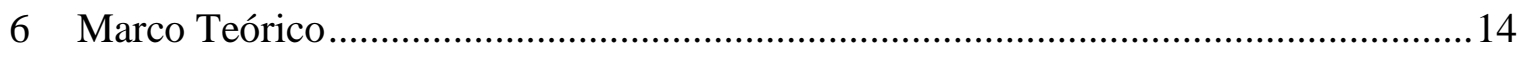

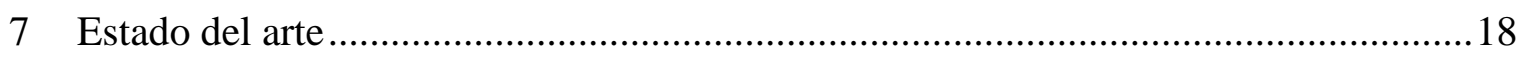

8 Contribución del proyecto a las líneas de investigación .........................................21

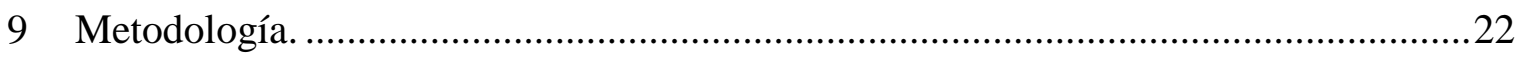

10 Producción de los Cultivos Transitorios en la Provincia del Alto Magdalena.........24

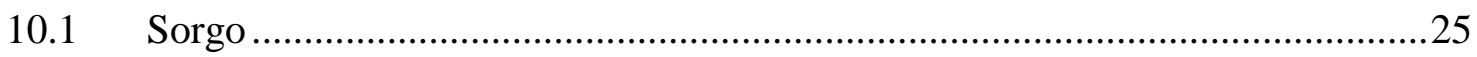

10.2 Maíz Amarillo Tradicional .....................................................................29

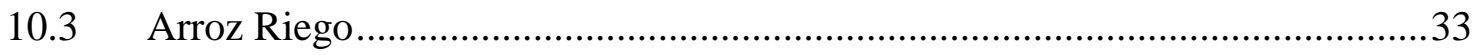

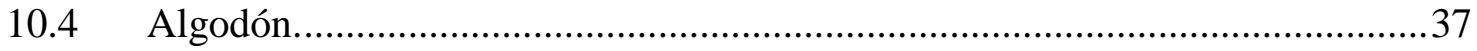

11 Función de producción cultivos transitorios provincia del Alto Magdalena ...........40

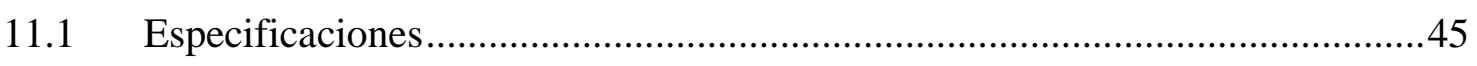

11.2 Resultados Encontrados ....................................................................... 46 


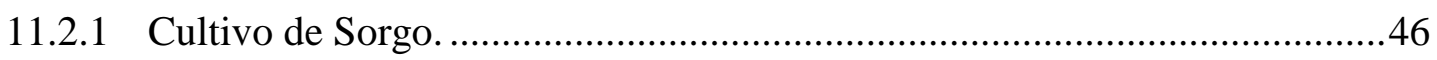

11.2.2 Cultivo de Maíz Amarillo Tradicional........................................................49

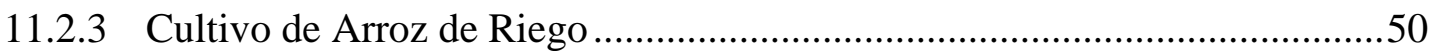

11.2.4 Cultivo de Algodón.................................................................................

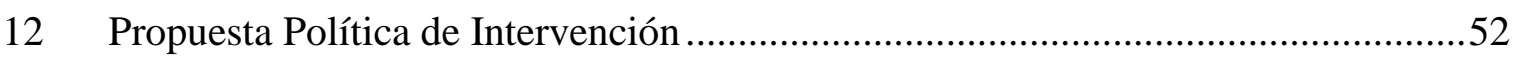

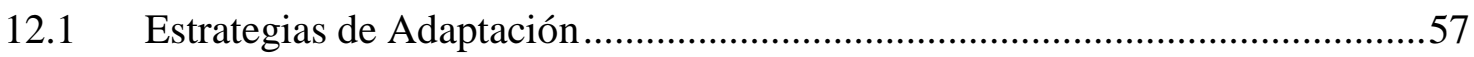

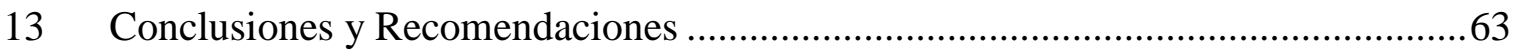

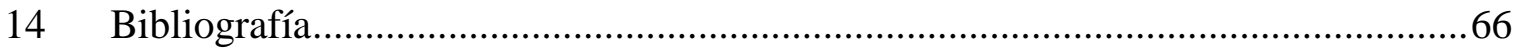




\section{TÍTULO}

Incidencia de las variables climáticas en los rendimientos de los cultivos transitorios en la provincia del Alto Magdalena para el periodo de 1992-2013

\section{Resumen del Proyecto}

Actualmente, el cambio climático es un fenómeno que ha cobrado mayor importancia porque afecta, notablemente, al sector agrícola y la seguridad alimentaria; lo que obliga a medir y cuantificar su impacto para la toma de decisiones. Así, el objetivo de este proyecto consiste en evaluar la incidencia de las variables climáticas (temperatura y precipitaciones) como razón del cambio climático, en los rendimientos de los cultivos transitorios en la provincia del Alto Magdalena, para el diseño de estrategias de adaptación al cambio climático.

De manera que la metodología utilizada para el cumplimiento de este objetivo se basa primero, en una recolección y análisis de datos de producción de los cultivos transitorios: maíz, sorgo, arroz y algodón; hectáreas sembradas y cosechadas en la provincia del Alto Magdalena, permitiendo hacer una caracterización y estimación de la función de producción, insertando las variables climáticas de temperatura y precipitación en la cual se estima sus impactos; segundo, la cuantificación del efecto económico del cambio climático en la producción agrícola y en los rendimientos de los cultivos transitorios, se hará bajo el Modelo Ricardiano "Este modelo se basa en la teoría de que, en mercados competitivos, el valor de la tierra representa el valor presente de los ingresos netos esperados derivado del uso eficiente de la tierra" Ramirez et al, (2010: 9). En la que las variables climáticas inciden en el valor económico del uso de la tierra, ya que, al existir cambios drásticos en estas variables, harán que los productores se sientan inducidos a hacer cambios en el uso del suelo afectando la seguridad alimentaria. 


\section{Palabras Claves:}

Rendimientos, Cambio Climático, Producción Agrícola, Función de Producción, seguridad alimentaria

\section{Planteamiento del Problema}

Con la Revolución Industrial a finales de siglo XVIII, la actividad humana toma un papel protagónico en la "acumulación acelerada de gases efecto invernadero (GEI), especialmente dióxido de carbono y metano". (Vargas, 2009), lo ha que producido un deterioro de la capa ozono, generando el fenómeno del "Cambio Climático”, que se traduce en cambios intensos de las variables climáticas (temperatura y precipitación) conocidos como fenómeno extremos ENOS (Niño y Niña). Estos cambios afectan directamente al sector agrícola, dado que este tiene una gran dependencia a las variables climáticas, impulsando una reducción en la producción y una disminución en los rendimientos de los cultivos; lo que afecta directamente el bienestar de los agricultores, provocando variaciones en la toma de decisiones en cuanto: al área de siembra, el uso del suelo y factores productivos como la ocupación de mano de obra no cualificada; puesto que los agricultores bajo escenarios climáticos extremos, no pueden generar suficientes ingresos, para suplir la disminución en la producción provocada por estos escenarios; esto hace que, como estrategia de adaptación, los agricultores migren hacia sectores más rentables y de menos ocupación (en términos de utilización de la tierra). Afectando la seguridad alimentaria; ya que al haber menos tierras disponibles para la agricultura y menos áreas sembradas implica una reducción de la oferta agrícola que disminuye el suministro a nivel local y aumenta los precios; pero eso no es todo; pues siguiendo la cadena de producción algunos bienes finales como losCereales- son el insumo para la alimentación animal que con un precio elevado induce al aumento en los costos de producción y por ende un aumento de los precios, lo que representa una 
canasta familiar más costosa, que disminuyen el acceso a los alimentos a las poblaciones más vulnerables.

La producción en el sector agrícola depende de factores socio-económicos y factores naturales, como el clima, pues "se tiene establecido que de manera recurrente, el clima presenta alteraciones transitorias o cambios de largo plazo que afectan la producción agrícola" Ruiz (2012); otra anomalía climática que afecta la producción son el Fenómeno ENOS (El Niño Oscilación del Sur), “pueden presentar tres distintas fases: 'El Niño' en años calientes, 'La Niña' en años fríos, o Neutro en caso de no registrarse variaciones significativas” Brescia, Lema y Parellada, (1998). Este fenómeno, entonces, tiene un impacto en el cambio de rendimientos de los cultivos y la ausencia de estrategias para adaptación hace a las regiones vulnerables, dado que no cuentan con la información suficiente, -que podría suministrarse con un sistema de alertas tempranas-, generando una incertidumbre para la toma de decisiones en escenarios climáticos extremos aumentando el riesgo de pérdidas en la producción y por ende en los beneficios económicos de los agricultores.

Además de lo dicho anteriormente, los Fenómenos ENOS ${ }^{1}$ también impactan en el sector agrícola generando situaciones de desastre; por lo que se requiere contar con estudios detallados a nivel regional que puedan cuantificar sus efectos en términos de rendimientos, para evaluar la incidencia que tienen las variables climáticas en la producción agrícola y en la afectación de los ingresos de los agricultores, con el objetivo de poder diseñar estrategias de adaptación para reducir sus efectos negativos e involucrar a los actores; pues la política de gestión de riesgo

\footnotetext{
${ }^{1}$ Según los datos históricos del Ideam, los cultivos más afectados por el fenómeno del niño han sido: fique, con una reducción anual promedio de 13\%; yuca y palma africana, con 8\%, y cebada, con 7\%, seguidos por arroz, papa, maíz, algodón, caña panelera, plátano, cacao y fríjol. Igualmente, la producción de leche podría verse afectada en 4,9\% en promedio". Ministerio de Agricultura y Desarrollo Rural (2012:5)
} 
entendida como las estrategias de adaptación, debe tener una connotación en la que los agricultores vean que están siendo atendidas sus necesidades y se está identificando su vulnerabilidad, lo que fortalece sus resiliencia ante escenarios de fenómenos ENOS.

La poca capacidad para el manejo efectivo de adaptación a las fluctuaciones climáticas y catástrofes por parte de los agricultores hacen que sean vulnerables y la falta de institucionalidad a nivel regional para generar, planificar y ejecutar estrategias concretas, aceleran los efectos que pueden tener el cambio climático, como es, temperaturas más altas y precipitación errática, que traerían como consecuencias “degradación del suelo y pérdida de materia orgánica, inundaciones, cambios en la prevalencia de plagas y enfermedades" (Lau, Jarvis, \& Ramirez , 2011), “disminución de la calidad de los cultivos, menor disponibilidad de tierra y recursos hídricos para la actividad agropecuaria" (Ortiz, 2012); y en cuanto no se te tengan cuantificado los efectos económicos de la incidencia de las variables climáticas en los ingresos de los productores agrícolas, no se generan incentivos para apropiarse de las estrategias de adaptación por parte de ellos.

En la actualidad esta problemática se sustenta a partir de la incidencia de factores antropogénicos y naturales y en la acumulación de gases efecto invernadero en la atmósfera terrestre; lo que ha hecho que diferentes actores de la comunidad nacional e internacional hayan implementado varias estrategias para evaluar el deterioro de los ecosistemas, la economía y la calidad de vida de las poblaciones, a partir del uso racional de los recursos, la mitigación del impacto ambiental y la gestión de riesgos frente a la ocurrencia de fenómenos extremos.

Siguiendo con lo expuesto por Instituto Internacional de Investigación sobre Políticas Alimentarias $^{2}$ (IFPRI, Washington DC), un aumento en la variable temperatura, puede ocasionar

${ }^{2}$ Cuya misión es brindar soluciones políticas que reduzcan la pobreza en los países en vías de desarrollo para garantizar la seguridad alimentaria, y es considerado como un centro de investigación agrícola 
pérdidas en la producción de los cultivos y un cambio en los régimen de lluvias aumentan la probabilidad de fracasos de las cosechas y una disminución en la producción, convirtiendo al sector agrícola muy sensible a los cambios de estas variables.

Las regiones también son susceptibles a las variaciones de la producción agrícola por razones climáticas, es así que la provincia del Alto Magdalena ubicada en el departamento de Cundinamarca, se puede ver afectada por la presencia de fenómenos climáticos extremos razón del planteamiento de este proyecto

La producción agrícola en la provincia se concentra en la siembra de: cereales $^{3}$ que representan el $44 \%$, frutales $31 \%$, otros permanentes ${ }^{4} 10 \%$, tubérculos y plátanos $6 \%$, hortalizas $5 \%$, fibras $2 \%$, y plantas aromáticas, condimentarías y medicinales $1 \%$; así las cosas resulta pertinente indagar el comportamiento de los cereales dado que, son los cultivos más representativos para la provincia y su siembra se hace de manera semestral convirtiéndolo en cultivos transitorios y que manejan estacionalidad por lo que se verían gravemente afectados por la presencia de fenómenos climáticos extremos.

En este contexto es importante hacer una descripción de la composición del grupo de los de los cereales, en la provincia; su siembra se concentra en los cultivos de sorgo con 41\%, maíz $29 \%$, arroz riego con $22 \%^{5}$; este tipo de cultivos tiene un sistema de siembra tradicional, lo que los hace vulnerables ante los cambios de las variables climáticas; adicional a esto, los cereales como el maíz y el arroz, son alimentos básicos de la canasta familiar, según estimaciones realizadas por FENALCE, el $80 \%$ de la producción nacional en el cultivo de maíz es destinado para el consumo humano y el $20 \%$ restante es utilizado por la industria de concentrados, siendo

\footnotetext{
${ }^{3}$ Se caracterizan porque la semilla y el fruto son lo mismo, e históricamente son alimentos que hacen parte de la dieta humana y animal

${ }^{4}$ Este grupo de cultivo acoge a: Cacao, Café y Caña para la provincia del Alto Magdalena.

${ }^{5}$ Estos porcentajes corresponde al periodo de análisis 1992-2013
} 
este cultivo importante para la alimentación de los colombianos y a nivel de provincia. Al igual que el maíz el cultivo de arroz es un producto tradicional e indispensable en la dieta alimentaria del colombiano y del provinciano del Alto Magdalena, gracias a su aporte en carbohidratos y su precio asequible; “de acuerdo con cifras suministradas por la Cámara del Arroz de la Asociación Nacional de Empresarios Andi, el consumo per cápita del cereal en Colombia asciende a 41 kilos por persona anualmente"; (Revista Dinero, 2015), bajo este contexto, nace la importancia de realizar la siguiente pregunta de investigación ¿Cómo se ven afectados los rendimientos agrícolas de los cultivos transitorios en la provincia del Alto Magdalena frente a las variables climáticas de temperatura y precipitaciones y cuáles serían las estrategias de adaptación al cambio climático?, teniendo en cuenta, que los cultivos transitorios están compuestos por cereales como: el arroz y el maíz y el sorgo, siendo estos alimentos que se encuentran presentes en la canasta familiar de manera directa e indirecta; como es el caso del sorgo ya que este cultivo es el suministro de para la elaboración de concentrados de consumo animal. 


\section{Objetivos}

\subsection{Objetivo General}

Demostrar la incidencia de las variables climáticas de temperatura y precipitación en los rendimientos de los cultivos transitorios en la provincia del Alto Magdalena, para el diseño de estrategias de adaptación al cambio climático.

\subsection{Objetivo Específicos}

4.2.1 Examinar el comportamiento de la producción de los cultivos transitorios en la provincia del Alto Magdalena para el periodo de 1992-2013.

4.2.2 Caracterizar y estimar la función de producción para los cultivos transitorios en la provincia del Alto Magdalena, insertando las variables climáticas de temperatura y precipitación.

4.2.3 Formular estrategias de adaptación al cambio climático para los cultivos transitorios de la provincia del Alto Magdalena.

\section{Justificación}

Históricamente, el sector agrícola se ha convertido en un dinamizador de la economía regional; ya que este garantiza el acceso universal a los alimentos, contribuye a la disminución de la pobreza al ocupar mano de obra no cualificada y permite un desarrollo territorial sostenible. Pero este sector, está siendo afectado por las variables climáticas; a consecuencia del calentamiento de la tierra, que ha desencadenado fenómenos climáticos extremos cada vez más frecuentes; que traen consigo sequias, inundaciones, aumento de plagas, cambios en los ciclos de los cultivos; generando escenarios de incertidumbres en los agricultores, que amenazan la oferta agrícola y la sostenibilidad de la economía regional. 
Teniendo en cuenta el contexto anterior, a nivel nacional se han gestado iniciativas para evaluar y medir el efecto del cambio climático; como es, la participación en la iniciativa "Estudio Regional de la Economía del Cambio Climático para Sudamérica $(E R E C C-S A)^{6}$ a través de estudios sectoriales, como: Impactos Económicos del Cambio Climático en Colombia (2014), estimando pérdidas anuales del PIB del 0,49\% a nivel agregado y para el sector agrícola una reducción de 7,4\% en los rendimientos anuales. También se encuentra el estudio Panorama del cambio climático en Colombia (2013), en el que se evidenció que el PIB bajo escenarios de presencia de cambio climático muestra una diferencia de 2,6\% frente al PIB potencial; otro aspecto importante que se ve afectado por el cambio climático, es la seguridad alimentaria; en un estudio realizado por Naciones Unidas en el 2012, se miden los efectos de la variabilidad climática sobre la disponibilidad de alimentos, en el cual se hace un mapeo a nivel departamental y municipal, sobre el grado de vulnerabilidad entendido como: "el porcentaje de personas que caerían en condiciones de indigencia o pobreza, cuando se da un aumento en el nivel de precios de la canasta de los alimentos" (Alfonso \& Alonso, 2012). Para el departamento de Cundinamarca se estimó que al aumentar en un $1 \%$ en el nivel de precios, los cundinamarqueses tienen la probabilidad de caer en condiciones de pobreza del 23,45\%. A nivel nacional se tiene un índice de vulnerabilidad del 34,57\%. Estos estudios expuestos anteriormente resaltan la incidencia que tiene el cambio climático a nivel económico como porcentaje de decrecimiento del PIB y a nivel social por la vulnerabilidad que pueden tener las familias más pobres ante un cambio de los precios por una contracción en la oferta agrícola, dado que las variables climáticas afectan directamente los rendimientos de los cultivos reduciendo la producción.

\footnotetext{
6 “Surge del interés común de los países de la región por analizar las consecuencias socio-económicas del cambio climático y desarrollar políticas de mitigación y adaptación, así como apalancar los recursos financieros necesarios para abordar este fenómeno. Los países que participan en este estudio son: Argentina, Bolivia, Chile, Colombia, Ecuador, Paraguay, Perú y Uruguay". (CEPAL, 2013) Este proyecto cuenta con la financiación de: La CEPAL, el BID y los gobiernos del Reino Unido, Dinamarca, España, la Unión Europea y Alemania
} 
Si bien a nivel nacional existe un gran avance en este tipo de investigaciones en la que se demuestran la relación entre el cambio climático, producción y los rendimientos agrícolas, estas investigaciones tienen un marco geográfico amplio dando una connotación general; por lo que se hace necesario realizar investigaciones que incluyan las particularidades de cada región, considerando que en la medida en que se logre establecer la relación que existe entre los fenómenos naturales y los hechos económicos de una determinada región, es posible que los agricultores, los policy makers, las autoridades, los empresarios y en general los habitantes de esa región adopten medidas oportunas para la mitigación de estos impactos.

Bajo estas condiciones se hace importante efectuar este tipo de investigaciones en la Provincia del Alto Magdalena, que se encuentra localizada en el departamento de Cundinamarca y está compuesta por los municipios de: Agua de Dios, Girardot, Guataquí, Jerusalén, Nariño, Nilo, Ricaurte y Tocaima; esta provincia emerge sus ventajas en dos grandes sectores, el turístico y agropecuario; esta dualidad está dada por la cercanía de los municipios a los ejes viales. Los municipios que han desarrollado una ventaja en el sector agropecuario, son los que se encuentran más alejados de los ejes viales y no cuentan con atractivos turísticos definidos, estos municipios son: Nilo, Nariño, Jerusalén, Guataquí y Agua de Dios; los municipios de Girardot, Ricaurte y Tocaima se encuentran sobre los ejes viables y son considerados como epicentro regional por lo cual toma fuerza el sector turístico en la provincia.

Aunque históricamente esta provincia era de vocación agrícola, esto ha venido cambiando por factores sociales y se ha ido convirtiendo en una región que orienta sus actividades hacia la prestación de servicios turísticos, -esta afirmación se basa, en lo que reza en el plan de competitividad de Girardot 2007-2019-; lo que ha contribuido a que el sector agrícola pierda importancia a pesar de que este transmite impactos socioeconómicos a la estructura regional. 
En la provincia del Alto Magdalena, una de las principales actividades de producción agrícola son los cereales con una participación del 59.85\% del total de área sembrada produciendo 28.709 ton para el año 201377 distribuidos en los cultivos de: maíz amarillo con 9.145 ton, maíz forrajero, 14.720 ton, arroz, 3.636 ton y sorgo con 1.209 ton. A nivel nacional los cereales cuentan con una participación secundaria del 24\% de área sembrada, después de otros cultivos permanentes con el $32 \%$.

Por tal razón se hace necesario realizar un análisis de la incidencia de las variables climáticas temperatura y precipitaciones sobre la producción agrícola de los cultivos que son de carácter transitorios como los cereales y las fibras, este tipo de cultivos se siembran de manera semestral lo que los hace más susceptibles ante factores externos como el clima, porque su ciclo vegetativo es más corto, el horizonte temporal de 1992-2013 se convierte en un periodo importante para la provincia, dado el contexto nacional que se vivó a principios de la década de los 90’como la apertura comercial en la que se inició un proceso de desregulación arancelaria, permitiendo a la industria realizar importaciones de materias primas como el maíz, algodón, sorgo, entre otros; provocando que el sector agrícola entrara en una reconversión, pues a principio de esa década este era considerado "un sector dinamizador de la economía regional, generador de riquezas y sustento diario de familias" (Cardenas, Gil, \& Mejia , 2009), haciendo que las actividades agrícolas quedaran rezagadas por la baja competitividad de los agricultores de la provincia. Otro aspecto importante para tener en cuenta, es que durante éste periodo de tiempo se vivieron los periodos de niño más fuerte que fueron en 1992 y 1997-1998, aunque se evidenciaron periodos de niños moderados para los años 2002 y 2005. Adicional a esto, no

\footnotetext{
${ }^{7}$ Datos obtenidos Evaluaciones Agropecuarias Municipales, Sistema de Información Estadístico Agronet.
} 
existen en la región estudios que evidencien la magnitud de la incidencia de las variables climáticas sobre los rendimientos de la producción de los cultivos transitorios.

Si bien en el cambio climático, al igual que con la mayoría de los fenómenos naturales, no resulta posible evitarlos, el hecho de establecer con certeza que ellos generan influencia en la economía permite generar estrategias de adaptación que mejoran las condiciones económicas de la población y de la región.

\section{Marco Teórico}

Para el cumplimiento del objetivo de esta investigación es importante abordar la teoría económica, con dos supuestos fundamentales primero los agricultores se ven enfrentados en un mercado donde no se tiene acción sobre el nivel de precios ni las cantidades a tranzar y segundo los agricultores se afrontan a limitaciones de tipo tecnológico y de mercado, en la que sus decisiones son de tipo de subsistencia y no de maximización de sus beneficios.

Lo que lleva a plantear la función de producción, que es una relación técnica que muestra como los factores de producción (tierra, trabajo y capital) son transformados y sus posibilidades técnicas.

La función de producción expresa, la máxima cantidad de producción que se puede producir con una cantidad determinada de factores de producción entendido como todo elemento que interviene en el proceso de producción, esta función se puede expresar como:

$$
Y=f\left(X_{1}, X_{2}, X_{3}, \ldots . X_{n}\right)
$$

Siguiendo con lo expuesto en el documento de la CEPAL Panamá Efectos del Cambio Climático sobre la Agricultura, en la que citan a los autores Fleischer y otros (2007) señala que la función de producción agrícola $(\mathrm{Q})$ “puede expresarse como una combinación de variables endógenas $(\mathrm{X})$ que pueden incluir trabajo, capital y otros insumos. En tanto que las exógenas $\mathrm{C}$ 
comprenden variables climáticas. Por su parte, las características de los agricultores $(\mathrm{Z})$ incluyen variables de capital humano.” (Mora et al 2010:25)

$$
Q_{t}=f\left(X_{1}, C_{1} Z_{1}\right)
$$

Y la función de beneficios del agricultor estaría dado por:

$$
\pi_{t}=\sum_{j=1}^{n}\left[P_{t} Q_{t}\left(X_{1}, C_{1} Z_{1}\right)-W_{t} X_{t}\right]
$$

En la que los agricultores buscan maximizar sus beneficios y eligen una combinación de insumos $X^{*}$ dada las variables exógenas. Con la combinación de sus factores fijos como tierra, maquinaria, mano de obra permanente y los factores variables como los insumos las semillas, fertilizantes, riego entre otros.

Al abordar la teoría de producción y cómo los agricultores maximizan sus beneficios teniendo en cuenta los factores de producción, es importante, concebir los conceptos de producto total, entendido como las cantidades de bienes para este caso toneladas de cultivo producidas con el aumento de un factor de producción, producto medio, es la producción por unidad del factor variable y producto marginal, es la producción adicional que produce una unidad adicional de un factor de producción mientras los demás permanecen constantes.

Es importante entender la ley de los rendimientos decrecientes, que expresa una relación básica que, al aumentar las unidades de un factor variable como trabajo, capital en términos de insumos, maquinaria agrícola y mantener una determinada cantidad de factor fijo, se llega un punto en el que la unidad adicional de factor variable genera una cantidad menor de producción. Siguiendo con lo propuesto por Sloman, (1997:181)

Esto quiere decir que en la producción agrícola "para determinado factor existe un máximo físico posible de usar a partir del cual la producción comienza a descender” RUIZ, (n.f), bajo esta ley se pretende hacer un análisis descriptivo, de la incidencia de las variables climáticas 
en los rendimientos de los cultivos transitorios. Aunque al hacer el análisis de la función de producción, con los conceptos de producción total, producción media, producción marginal y ley de rendimientos decrecientes, permite medir la relación entre los rendimientos del cultivo de los cultivos transitorios en la provincia del Alto Magdalena y las condiciones climáticas; la función de producción no captura por completo la adaptación y estrategias previas con las que cuentan los agricultores para mitigar el impacto del cambio climático.

Adicional a lo dicho anteriormente se hace necesario realizar otro análisis a través del Modelo Ricardiano, en el cual se estiman las estrategias de adaptación que tienen los agricultores frente al cambio climático, como son el cambio del uso del suelo, bien sea para la siembra de cultivos más resistentes a las variables climáticas o en definitiva cambiar el uso del suelo bien sea para uso recreativo o residencial.

Los enfoques utilizados para el cálculo de los efectos de cambio climático sobre rendimientos agrícolas y el sector agrícola se dividen en dos: estructurales y espaciales el primer enfoque está encaminado hacia combinar respuestas físicas de los cultivos con las decisiones económicas de los agricultores, cuenta con ventajas como información detallada de las respuesta físicas y biológicas; el enfoque espacial en el que "explota las diferencias observadas en la producción agrícola y el clima entre regiones.” Ramirez Et al, (2009:7) este enfoque permite determinar los efectos del cambio climático, contrastando variables como tierra y producción agrícola, con la utilización de modelos agrupados bajo este enfoque, se hace la inclusión de las estrategias de adaptación y mitigación del impacto del cambio climático que tiene los agricultores.

Uno de los modelos más utilizados bajo el enfoque espacial y que mide el impacto de los efectos económicos del cambio climático en el sector agrícola es el "Modelo Ricardiano desarrollado por (Mendelsohn et al. 1994), en el que se tiene en cuenta el valor del uso del suelo, 
frente a la productividad del cultivo, pues estudia la relación entre la producción agrícola y las variables climáticas siendo un modelo de corte trasversal, lo dicho anteriormente se basa en lo propuesto por (Oliviera, 2013:8)

El modelo Ricardiano, se basa en teoría de las ventajas comparativas, que analiza la productividad de los factores, para el caso de estudio el factor tierra-, los agricultores miden como estrategia de adaptación al cambio climático, el uso del suelo y frente a las alternativas que tienen toma su mejor opción; como puede ser, siembra, urbanización, ganadería entre otras. Pues partiendo del supuesto en el que el agricultor actúa como una agente racional, en la que eligen de manera relativa cual es la opción en la obtiene mayores beneficios al trasladar la frontera de producción.

Este modelo permite observar como las variables climáticas afectan el valor de las tierras cultivadas proporcionando herramienta de análisis en la que los agricultores poseen la posibilidad de responder a los cambios de las variables climáticas, mediante la búsqueda de una mayor renta de la tierra como estrategia de adaptación.

La demostración matemática del modelo Ricardiano es la siguiente: Siguiendo lo propuesto por Mendelsohn et al. 1994

$$
\pi=\sum P Q(X, C, Z)-\sum w_{x} x
$$

Donde: $\pi$ es la maximización del ingreso de los agricultores, en que el valor de la tierra muestra su productividad mediante el ingreso neto de la tierra.

$P$, es el precio de mercado del cultivo

$Q$, es la cantidad ofertadas

$X$, vector de insumos

$C$, variables climáticas 
$Z$ Vector de otras variables que afecta la producción del cultivo.

$w_{x}$ Vector de precios de los insumos.

La expresión econométrica sería la siguiente:

$$
L V=\beta_{0}+\beta_{1} T+\beta_{2} T^{2}+\beta_{3} P+\beta_{4} P^{2}+\beta_{5} T \cdot P+\sum \delta_{j} \cdot Z+e
$$

Donde la estimación del valor de la tierra está dada por las variables climáticas,

temperatura y precipitación, la sumatoria de $\delta_{j} . Z$ reúne el conjunto de variables socioeconómicas y características de suelos y e es el error. Los términos cuadráticos es la posibilidad que existe que el valor de la tierra no responda de manera lineal ante las variables climáticas.

\section{$7 \quad$ Estado del arte}

El cambio climático es un fenómeno ambiental que afecta de manera severa la producción de bienes y servicios. Al respecto, Stern (2007) afirma que:

Los problemas del cambio climático son actualmente convincentes, hasta el punto de justificar la aplicación de medidas contundentes de reducción de las emisiones de gases invernadero a nivel global y mitigar el impacto negativo y potencialmente irreversible en los ecosistemas, las sociedades y las economías.

Frente a este fenómeno se han realizado una serie de estudios y modelos que llevan a la evaluación y cuantificación del impacto del cambio climático en diferentes sectores de la economía, quizás el más afectado es el sector agrícola, el clima juega un papel importante en los rendimientos de su producción, ya que el aumento sostenido de la temperatura, humedad del suelo y/o variación en las precipitaciones afectan directamente el crecimiento del cultivo. Así lo evidencian los estudios y discusiones académicas realizadas en países como Estados Unidos, Sudáfrica y Latinoamérica, en torno al efecto negativo que tiene el cambio climático en la 
agricultura, donde se concluye que las buenas prácticas en este sector contribuirían a mitigar el calentamiento global.

En este punto, podría afirmarse que el clima se considera como una variable exógena determinante para los rendimientos agrícolas; lo que ha despertado interés por parte de la comunidad científica desde hace ya varios decenios.

Fue precisamente durante la década de los años setenta que se efectuaron los primeros estudios sobre "el uso de modelos de regresión para inferir relaciones estadísticas entre el clima y sus efectos potenciales en los rendimientos agrícolas" (Conde, y otros, 2004:105); los cuales fueron denominados modelos agroclimáticos caracterizándose porque se centran en realizar seguimiento a los cultivos y pronósticos de rendimiento como a la productividad potencial de los mismos.

El primer estudio aplicando el modelo Ricardiano, fue el realizado por Mendelsohn et al 1994, en el que se examinó el impacto de las variables climáticas y otras variables como: el valor de la tierra y los ingresos agrícolas, considerando las posibilidades de adaptación que tiene los agricultores y el uso que pueden hacer del suelo para la siembra y cosecha de sus cultivos; para el sector agrícola de Estados Unidos.

Por otra parte, la investigación realizada por Adams, Chen, \& McCarl Bruce (1999) desarrolla estimaciones de las consecuencias económicas del fenómeno ‘El Niño’ para el periodo de (1997-1998) en la agricultura estadounidense; tales estimaciones se elaboraron en dos etapas, la primera se basa en un modelo de simulación de cultivos en la que se evaluaron las consecuencias de Fenómenos ENOS en los rendimientos de ocho tipos de cultivos (maíz, trigo, soya, algodón, cebada, sorgo, avena y heno) utilizando un modelo de simulación biofísico 
llamado $\mathrm{EPIC}^{8}$ (Erosion Productivity Impact Calculator). En la segunda, los autores evalúan el rendimiento de los cultivos para un periodo de 25 años teniendo en cuenta las variables económicas.

Sumado a lo anteriormente expuesto, también existen modelos globales como los realizados por Jury (2002) en zonas áridas de Sudáfrica donde se evalúan los rendimientos del cultivo de maíz en función de las variables climáticas (las precipitaciones y la temperatura), variables hidrológicas (el abastecimiento de agua) y las variables económicas (Producto Interno Bruto) para el periodo de 1971-1993, donde el objetivo central de este estudio consistía en evaluar qué tan vulnerable era la economía sudafricana al cambio climático.

En Latinoamérica se han realizados estudios bajo el Modelo- Ricardiano, como el realizado por Gonzalez \& Velasco (2007) en la que determinaron la relación existente entre los sistemas agropecuarios de Chile y el cambio climático, en la que explican el comportamiento de la variable uso del suelo en función de las variables climáticas, desde el punto de vista del productor, en la que este se adecua sus decisiones del uso del suelo teniendo en cuenta las variables climáticas, insumos y condiciones de mercado.

Bajo este mismo enfoque están los estudios realizado por la CEPAL, Efectos del Cambio Climático sobre la Agricultura para Panamá y Centroamérica, (2010) en la que evalúan los efectos de las variables climáticos, bajo dos enfoques, el primero desde producción agrícola con la estimación de la función de producción y el segundo una evaluación de los efectos sobre los ingresos de los agricultores evaluando el valor del uso del suelo bajo la estimación del modelo Ricardiano.

8 “Desarrollado por Williams (1984) con la finalidad de contar con una herramienta para la determinación de la influencia de las pérdidas de suelo en los procesos productivos". Rojas (1999:10) 
En este tipo de análisis resulta clave el comportamiento del productor frente a variables exógenas como la precipitación y temperatura, que repercuten finalmente en el precio; la eficiencia económica que "corresponde a la existencia entre la cantidad de producción y disponibilidad a pagar, y la otra, entre la producción y los costos marginales de producción" Field \& Azqueta, (1996).

Luego, para estimar el impacto del cambio climático, se debe tener en cuenta cómo toman decisiones las familias y los productores logrando la eficiencia del mercado, pues las primeras son los agentes económicos que están dispuestos a pagar y los segundos -dependiendo de su costos marginales- producen logrando un nivel socialmente eficiente.

En el ámbito nacional y sectorial, los autores Bonilla, Rosales, \& Maldonado (2003) realizaron estimaciones sobre el valor económico del mejoramiento de predicción del fenómeno 'El Niño Oscilación del Sur' proveída por un sistema de alerta temprana para el sector azucarero colombiano; este tuvo en cuenta las características agronómicas y económicas de la producción de caña de azúcar para evaluar las implicaciones de bienestar y el valor de la predicción.

En consecuencia, dado que los fenómenos ‘El Niño y La Niña’ están asociados con el aumento o disminución anómalo de la temperatura superficial del mar, uno de los indicadores más utilizados para hacer seguimiento es el Índice del Niño Oceánico (ONI, por sus siglas en inglés), desarrollado por la National Oceanic and Atmospheric Administration (NOAA). Este índice es calculado a partir de mediciones de la temperatura superficial del mar, en el sector central del Pacífico tropical frente a las costas de Suramérica.

\section{Contribución del proyecto a las líneas de investigación}

Esta investigación busca generar capacidades de adaptación en los agricultores de la región del Alto Magdalena ante factores externos como el clima, mejorando su bienestar; 
formulando una política de intervención en la que se unen los esfuerzos públicos y privados para lograr un empoderamiento de los agricultores de la provincia y de esta manera contribuir en una mejor distribución de los recurso; bajo este esquema de investigación se pretende contribuir a la línea de investigación Economía Social.

\section{Metodología.}

Con el fin de dar respuesta a la formulación y sistematización del problema planteado en la descripción del proyecto, esta investigación se ubica en el enfoque descriptivo, ya que procede a comprobar la relación que existe entre los rendimientos de los cultivos transitorios en la provincia del Alto Magdalena tanto en las variables económicas, como las variables climáticas.

Para lograr lo anteriormente mencionado, resulta indispensable iniciar con el análisis de la producción de los cultivos transitorios en la provincia del Alto Magdalena, considerando la teoría de producción y la función plantea en el marco teórico, esta investigación pretende analizar en una primera parte los efectos de las variables climáticas sobre los producción agrícola de los cultivos transitorios sorgo, maíz, arroz y algodón en la provincia de Alto Magdalena, a partir de índices de producción, Se plantea la siguiente ecuación:

$$
\begin{gathered}
Q_{\text {Sorgo }}=\beta_{0}+\beta_{2} T+\beta_{3} P+\beta_{4} A+e \\
Q_{\text {Maiz }}=\beta_{0}++\beta_{2} T+\beta_{3} P+\beta_{4} A+e \\
Q_{\text {Arroz }}=\beta_{0}++\beta_{2} T+\beta_{3} P+\beta_{4} A+\beta_{5} L+e \\
Q_{\text {Algodón }}=\beta_{0}++\beta_{2} T+\beta_{3} P+\beta_{4} A+e
\end{gathered}
$$

Donde:

T: Promedio Temperatura

P: Promedio Precipitaciones

A: área Sembrada 
Como el productor se enfrenta a escenarios de incertidumbre en el momento de la toma de decisiones para cultivar, las variables climáticas se convierten en un factor importante para la maximización de sus beneficios; por lo tanto, toma relevancia, la identificación del comportamiento de las variables y las causas asociadas a la fluctuación del clima en las últimas décadas para de esta manera, reunir las variables económicas y variables climáticas.

Al realizar el respectivo análisis y agrupación de datos, se procederá a la implementación y validación modelo Ricardiano, para la medición del impacto del cambio climático sobre los ingresos de los agricultores de los cultivos de transitorios en la provincia del Alto Magdalena.

La expresión econométrica sería la siguiente:

$$
L V=\beta_{0}+\beta_{1} T+\beta_{2} T^{2}+\beta_{3} P+\beta_{4} P^{2}+\beta_{5} T . P+\sum \delta_{j} . Z+e
$$

Donde la estimación del valor de la tierra está dada por las variables climáticas, temperatura y precipitación, la sumatoria de $\delta_{j} . Z$ reúne el conjunto de variables socioeconómicas como el precio del mercado nacional, el costo de los insumos, alquiler de maquinaria para la recolección de la siembra, características del suelo y $e$ es el error. Los términos cuadráticos so la posibilidad que existe de que el valor de la tierra no responda de manera lineal ante las variables climáticas.

Con los datos suministrados por el sistema de información estadístico del Ministerio de Agricultura (Agronet) y secretaria de agricultura Gobernación de Cundinamarca, se realiza la validación de los modelos utilizando el programa estadístico STATA 12 ®, el cual permitirá realizar las diferentes estimaciones. Las pruebas econométricas y los análisis de regresión seguirán la metodología de datos de panel, para el periodo de 1992-2013. 


\section{Producción de los Cultivos Transitorios en la Provincia del Alto Magdalena.}

Los cultivos transitorios, se definen como aquellos, cuyo ciclo vegetativo es menor a un año y "se caracterizan porque al momento de la cosecha son removidos y para obtener una nueva cosecha es necesario volverlos a sembrar". (DANE, 2007), para hacer el análisis anual ${ }^{9}$ de estos cultivos se realizó la suma del semestre $\mathrm{B}^{10}$ del año anterior más el semestre $\mathrm{A}^{11}$ del año en referencia; siguiendo con lo propuesto por la ficha técnica de Evaluaciones agropecuarias Municipales de 2013, esta sumatoria corresponde a lo que se denomina año agrícola.

En la provincia del Alto Magdalena del departamento de Cundinamarca, los cultivos transitorios con mayor relevancia para el periodo de estudio son: algodón 4,7\%, arroz riego 18,2\% maíz 27,2\% y sorgo 42,4\% del total de producción como se pude observar en la Figura 1.

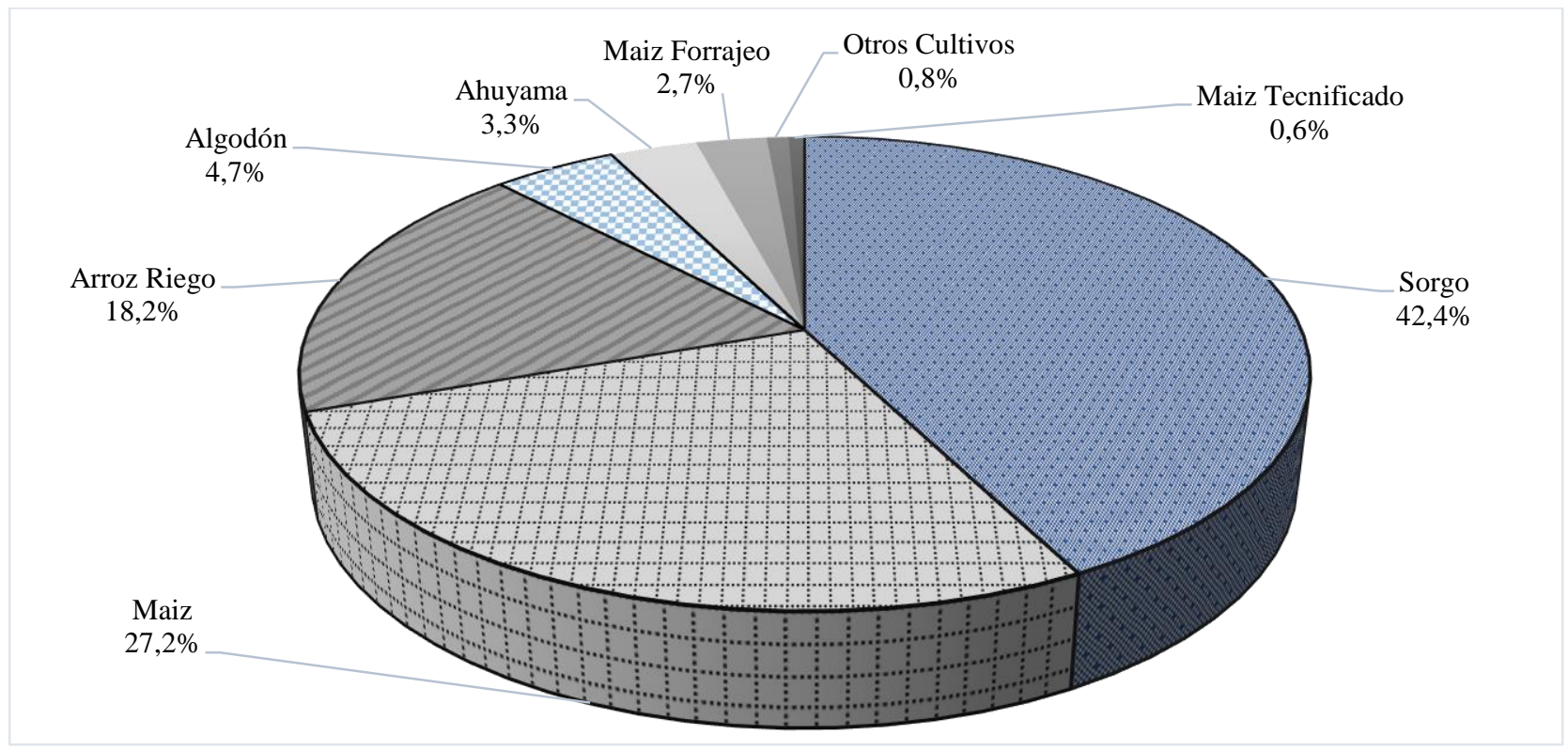

Figura 1. Producción de cultivos Transitorios en la Provincia del Alto Magdalena

Fuente: Evaluaciones Agropecuarias Municipales, Estadísticas Agropecuarias, Secretaria de Agricultura y Desarrollo Económico. Gobernación de Cundinamarca. Elaboración propia

9 “Ejemplo: Para el área o producción del año 2011 se suma el área o producción del semestre B del año 2010 más el área o producción de semestre A del año 2011 l’. (Ministerio de Agricultura y Desarrollo, 2014)

${ }^{10}$ Compuesto por los meses: Julio, Agosto, Septiembre, Octubre, Noviembre y Diciembre

${ }^{11}$ Compuesto por los meses: Enero, Febrero, Marzo, Abril, Mayo y Junio 
Este capítulo se dividirá en cuatro partes, en la que se estudiará el comportamiento de la producción de los rendimientos de los principales los cultivos transitorios Sorgo, Maíz Tradicional, Arroz Riego y Algodón que se cosechan en la provincia, haciendo un comparativo entre los municipios y rendimiento a nivel provincia.

\subsection{Sorgo}

El sorgo, es un cultivo que se utiliza principalmente como materia prima en la producción de alimentos balanceados para animales, que en términos de producción ocupa el cuarto lugar a nivel mundial, después del arroz, trigo y maíz. A nivel nacional su producción y siembra se concentra en los departamentos del Tolima y Valle del Cauca; el departamento de Cundinamarca tiene una participación baja a nivel nacional, pero a nivel de la provincia del Alto Magdalena este cultivo toma un papel protagónico, pues es, la única provincia del departamento en la que se siembra y se produce; siendo un cultivo de rotación para el arroz y el algodón, dada su fácil adecuación a temperaturas altas y déficit hídrico.

En la figura 2 se puede observar el comportamiento de la producción para el periodo de 1992-2013; a principios de los 90, este cultivo empezaba a consolidarse, ya que se logró una producción de 762.000 Ton a nivel nacional, según lo expuesto por FENALCE en su revista número 93 de 2010. Pero con las nuevas políticas de liberación comercial de esa década, que consistían en la reducción de carga alancearía para las materias primas, la industria alimentaria especialmente la avícola sustituyó la compra de sorgo, por maíz amarillo importado, generando un estancamiento de los precios interno y des estimulación en la siembra y producción de este cultivo. 


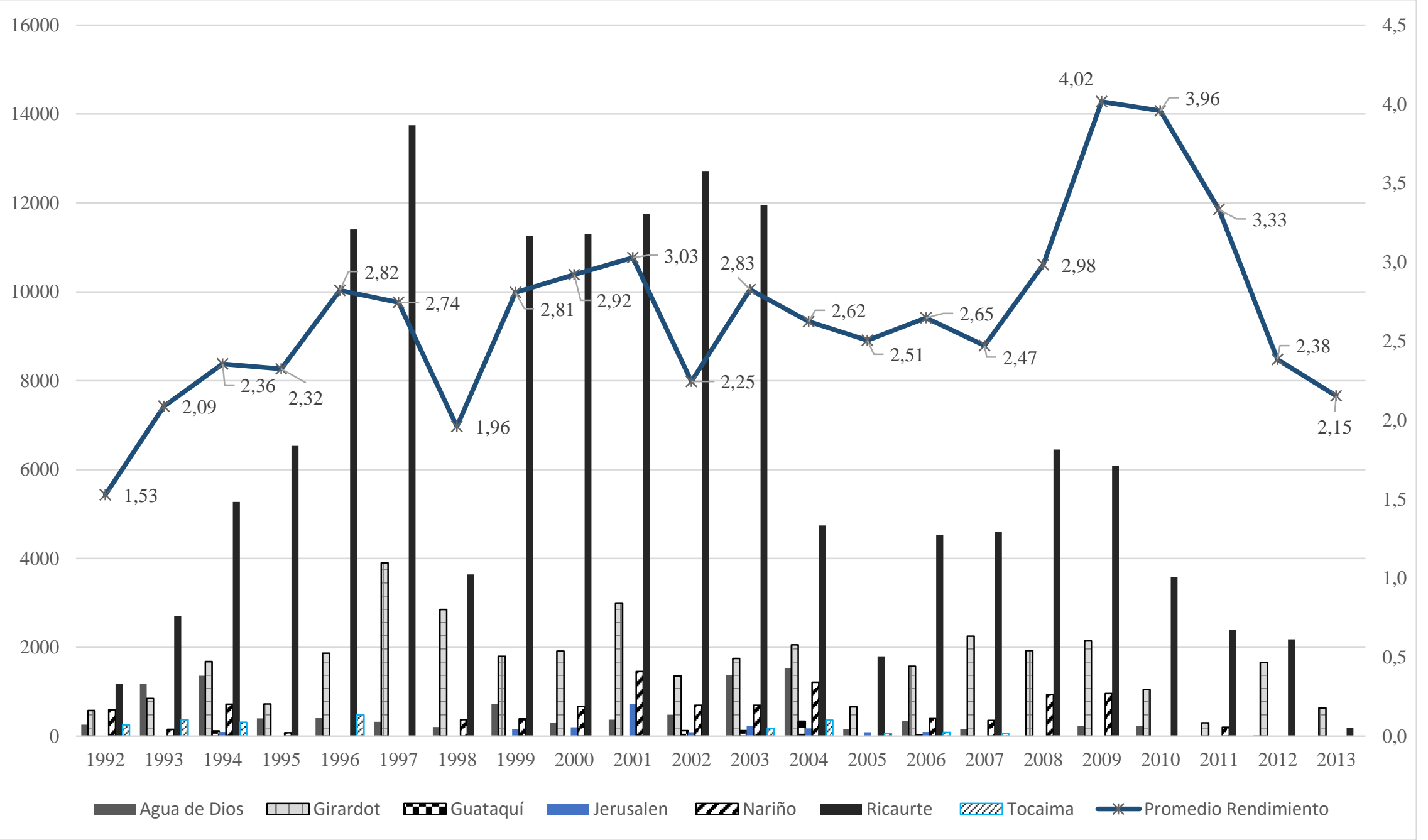

Figura 2. Producción total de Sorgo periodo 1992-2013. Redimiendo Promedio provincia Alto Magdalena

Fuente: Evaluaciones Agropecuarias Municipales, Estadísticas Agropecuarias, Secretaria de Agricultura y Desarrollo Económico.

Gobernación de Cundinamarca. Elaboración propia 
Para de 1992, el sorgo presenta uno de los rendimientos más bajos rendimiento de 1, 53 Ton/ha., causado por la presencia del fenómeno del ‘Niño’ que se tradujo en la disminución de las precipitaciones y aumento de las temperaturas, principal municipio productor es Ricaurte con 1, 185 Ton., seguido por Nariño con 595 ton., Girardot 581 ton., Agua de Dios 261 Ton. Y finalmente Tocaima con 255 Ton. para un total de 2.877 Ton para un área cosechada de 1884 Ha.

Para los años, 1993 y 1994, el sorgo tuvo un comportamiento similar, con la participación de los municipios de Agua de Dios, Girardot, Nariño y Ricaurte, los costos de producción se mantuvieron, pero el precio al productor fue bajo y no era competitivo para los agricultores de la provincia; para el año de 1997, se empiezan a sentir las primeras consecuencias ocasionada por el Fenómeno del Pacífico ‘Niño’ en la que se ve una ligera reducción del rendimiento de -2,74\%.

En el año de 1998, se presentó una drástica caída del área sembrada, con respecto al año anterior de 6.833 Hectáreas sembradas pasó a 3.618 hectáreas con una disminución del 47.1\%, como consecuencia del fenómeno del Pacifico 'Niño', generando una fuerte reducción de rendimiento.

Para los años 1999, 2000 y 2001 se presentan una estabilidad en la producción con rendimientos entre 2,82 Ton/Ha. y 3.03 Ton/Ha. El año 2002 registró una nueva disminución en el rendimiento del cultivo ocasionado por dos factores, el primero por la escasa precipitación en el primer semestre y segundo en el municipio productor de Agua de Dios tiene pérdidas totales de 50 hectáreas para el segundo semestre ocasionado por las fuertes lluvias. 
El 2005 representa un año con una fuerte caída de producción y del rendimiento del cultivo a causa de las expectativas de bajos precio final al productor y los problemas de comercialización, dado que este cultivo tiene un bien sustituto que es el maíz amarillo.

A partir del año 2008, las áreas de siembra y cosecha tienen una reducción notable del $30 \%$, lo que lleva una reducción de producción del 25\%, para el año 2009 se presenta uno de los rendimientos más altos de la provincia jalonado por las condiciones climáticas.

Durante los años 2010, 2011, 2012 y 2013, el cultivo de sorgo tuvo una tendencia decreciente en las variables de producción y rendimientos, por factores externos como el cambio del uso del suelo en la provincia, disminución de la carga arancelaria para la importación de cereales, hay hecho que exista un desincentivo para la producción de este cereal. 


\subsection{Maíz Amarillo Tradicional}

El cultivo de maíz, es uno de cereales más consumidos a nivel mundial, utilizado para la alimentación humana y animal, y usos industriales en la producción de almidón, fabricación de edulcorantes, aceites, alcohol etílico entre otros; adicional a esto este cultivo tiene una fácil adaptación a las condiciones climáticas. Este cultivo a nivel regional ocupa el $45 \%$ de la extensión de tierras sembrada para los cultivos transitorios y a nivel nacional el 37\%, también es importante en la generación de empleo no cualificado dado que la técnica de sembrado para la provincia del alto de Magdalena se hace de manera tradicional que se caracteriza por la ausencia de mecanización.

Los rendimientos agrícolas de este cultivo a nivel regional en promedio para el periodo de estudio 1992- 2013 fue de 1.6 Ton/Ha, muy por debajo del rendimiento del mayor productor Estados Unidos de 9.3 Ton/Ha según datos FENALCE, lo cual lo hace poco competitivo para los agricultores de la región, pero debido a su fácil adaptación a los condiciones climáticas de la región y tradición de siembra, hace que este cultivo ocupe una importante extensión tierra y se situé en el segundo lugar en la producción de cultivos transitorios en la provincia con 171.089 Ton y a diferencia de los otros cultivos transitorios, en la siembra y producción participan siete de los ocho municipios que conforman la provincia que son Agua de Dios, Girardot, Guataqui, Jerusalén, Nariño, Ricaurte y Tocaima.

El municipio con mayor producción es Jerusalén con 61,610 Ton. y 35.341 Ha sembradas, seguido por Tocaima con 39.244 ton. y 30.880 Ha, si se mira la relación entre la producción y área sembrada en el municipio, se puede asumir que éste, tiene bajos rendimiento de apenas 1.3 Ton/Ha. como se puede observar en la Tabla 2. Siguiendo con el análisis el tercer municipio productor es Guatqui con 28. 317 Ton y 15.494 Ha, sucesivo por el municipio de Nariño y Ricaurte este municipio tiene el rendimiento más alto con 1.9 Ton/Ha. pero no es uno de los 
grandes productores con 9.054 ton y 4.886 ha. Finalmente están los municipios de Girardot y

Agua de Dios con rendimientos de 1.6 Ton/ha y 1.7 Ton/ha respectivamente.

Tabla 1. Producción y Área sembrada por municipio

\begin{tabular}{cccc}
\hline Municipio & Producción & Área cosechada & Rendimiento \\
\hline Jerusalén & 61,610 & 35,341 & 1.7 \\
Tocaima & 39,244 & 30,880 & 1.3 \\
Guataqui & 28,317 & 15,494 & 1.8 \\
Nariño & 26,906 & 15,479 & 1.7 \\
Ricaurte & 9,054 & 4,886 & 1.9 \\
Girardot & 4,853 & 3,053 & 1.6 \\
Agua de Dios & 1,105 & 635 & 1.7 \\
\hline Total general & $\mathbf{1 7 1 , 0 8 9}$ & $\mathbf{1 0 5 , 7 6 8}$ & $\mathbf{1 . 6}$
\end{tabular}

Fuente: Evaluaciones Agropecuarias Municipales, Estadísticas Agropecuarias, Secretaria de Agricultura y Desarrollo Económico. Gobernación de Cundinamarca. Elaboración propia

En la figura 3 se puede observar que los años 1992, 1998 y 2005, presentaron los rendimientos más bajos para el periodo de estudio, estos decrecimientos en los rendimientos; fueron causados en gran parte por la presencia de Fenómeno del Pacífico 'Niño' y al aumento de los costos de producción 
6000

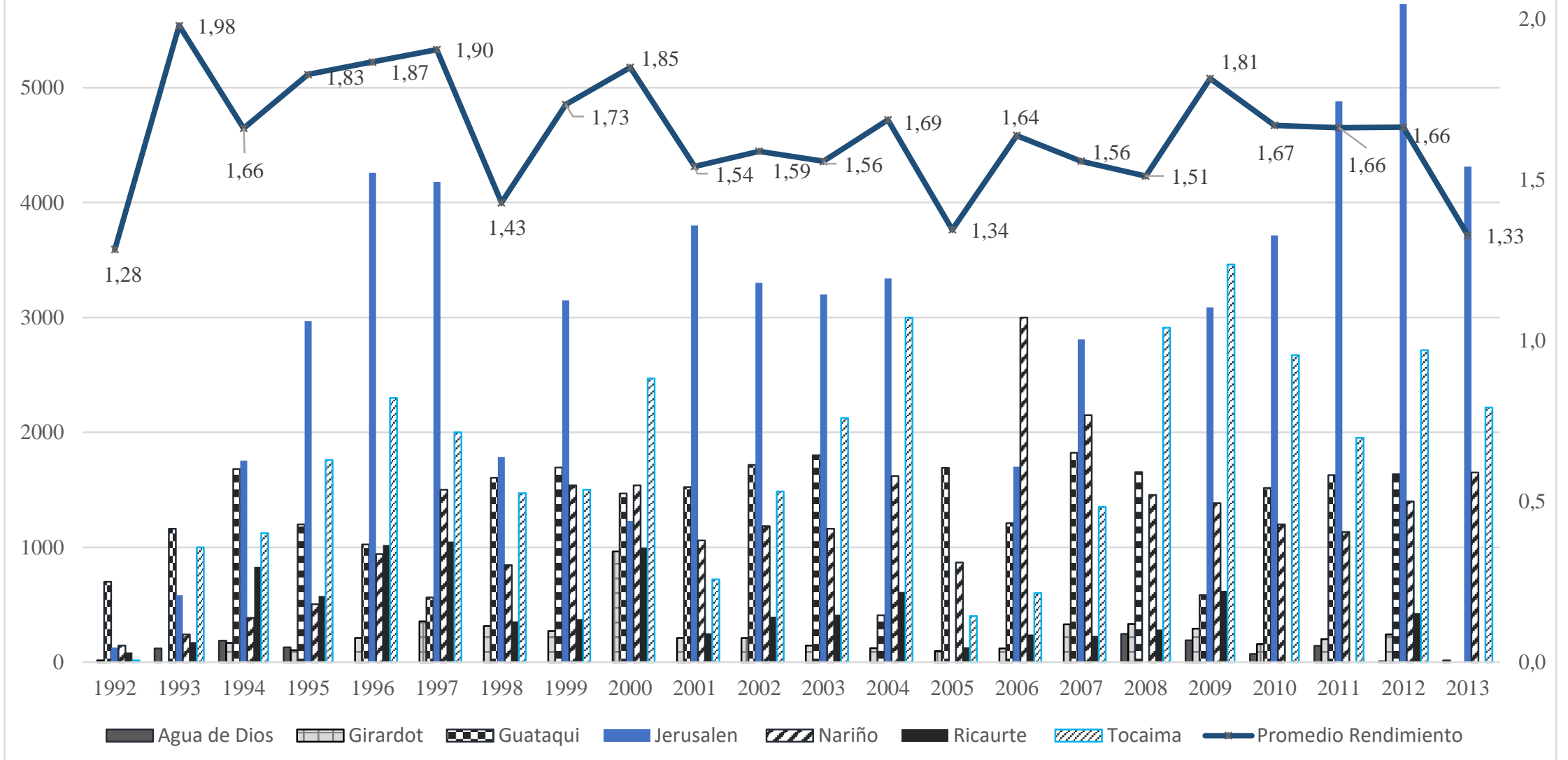

Figura 3. Producción total de Maíz Amarillo Tradicional periodo 1992-2013. Redimiendo Promedio provincia Alto Magdalena

Fuente: Evaluaciones Agropecuarias Municipales, Estadísticas Agropecuarias, Secretaria de Agricultura y Desarrollo Económico. Gobernación de Cundinamarca. Elaboración propia 
La producción de maíz, a inicios de los años 90’ presentó un crecimiento positivo alcanzando su punto máximo en el año de 1997 con un total de 10.108 ton y con la participación de los municipios de Girardot, Guataqui, Jerusalén, Nariño, Ricaurte y Tocaima.

Para el año de 1998 se registró un gran decrecimiento en el nivel de producción del 47.2\%, causado por la presencia del Fenómeno del Pacifico 'Niño', unido a esto, la escasez de mano de obra y los altos costos de producción hicieron que no fuera un buen año para los agricultores de este cultivo y el rendimiento por hectárea fue de 1,43 uno de los más bajos del periodo de estudio.

En 1999 se presentó la recuperación tanto en área sembrada como en producción, esta aumenta un 58\%, pero es debido al fuerte decrecimiento del año anterior, ya que la producción para este año fue de 8.441 ton, lo que en promedio se produjo en la provincia del Alto Magdalena.

El nuevo siglo trae una estabilización para el rendimiento por hectárea como se puede observar en la figura 3. Para el año 2005 se registró un nuevo decrecimiento tanto para la producción como para los rendimientos del cultivo, dado que este año fue determinado como uno de las más cálidos en el siglo XXI, por lo que se puede inferir que las variables climáticas climática como la temperatura tiene una fuerte influencia en los rendimientos y producción de los cultivos en la provincia.

Para los siguientes años 2006-2013, la provincia binó presentando un cambio en el uso del suelo y la vocación de la provincia se está inclinando hacia la prestación de servicios turísticos y segunda residencia, lo que ha hecho que exista una expansión de nuevos proyectos de construcción reduciendo la disponibilidad de tierra para sembrar. 


\subsection{Arroz Riego}

El cultivo de arroz, es considerado uno de los cereales más importantes para la alimentación humana; en su producción se combina trabajo, tierra y recursos naturales como el agua, siendo este muy importante para su rendimiento; en la provincia del Alto Magdalena, la técnica de sembrado que se utiliza es riego ${ }^{12}$, siendo necesario tener un sistema de fijo de alimentación de agua para su siembra, germinación y crecimiento de la planta, este cultivo se cultiva, de manera semestral en ambientes tropicales y subtropicales, y dependen de variables climáticas como la temperatura, pues "necesita para germinar un mínimo de 10 a $13{ }^{\circ} \mathrm{C}$, considerándose su óptimo entre 30 y $35^{\circ} \mathrm{C}$. Por encima de los $40^{\circ} \mathrm{C}$ no se produce la germinación". (FINAGRO, N.F) Convirtiendo el arroz en un cultivo muy susceptible al cambio de la variable temperatura.

Este cereal concentra su producción en los municipios de Tocaima con una participación del 46\% y Ricaurte 36\%; los municipios de Guataquí, Girardot, Agua de Dios y Nariño representan el 18\% del total de la producción, es importante aclarar que estos municipios cultivaron este cereal hasta el año de 1995, excepto Girardot, que reanuda su producción para los años 2004- 2009, como se puede observar en los datos suministrados por la Tabla 2.

12 "Es aquel en el que el agua que requiere el cultivo es provista por el hombre en cualquier momento, y puede hacerse por bombeo o gravedad (ya sea que el agua provenga de distritos de riego públicos o privados, o de pozos), o por inundación o fangueo". (FINAGRO, N.F) 
Tabla 2. Producción y Área Sembrada Cultivo de Arroz. Provincia del Alto Magdalena

\begin{tabular}{|c|c|c|c|c|c|c|c|c|c|c|c|c|c|c|}
\hline \multirow{2}{*}{ Años } & \multicolumn{2}{|c|}{$\begin{array}{c}\text { Agua de } \\
\text { Dios }\end{array}$} & \multicolumn{2}{|c|}{ Girardot } & \multicolumn{2}{|c|}{ Guataqui } & \multicolumn{2}{|c|}{ Nariño } & \multicolumn{2}{|c|}{ Ricaurte } & \multicolumn{2}{|c|}{ Tocaima } & \multirow{2}{*}{$\begin{array}{l}\text { Total } \\
\text { Prod. }\end{array}$} & \multirow{2}{*}{$\begin{array}{l}\text { Total } \\
\text { Área }\end{array}$} \\
\hline & Área & Prod. & Área & Prod. & Área & Prod. & Área & Prod. & Área & Prod. & Área & Prod. & & \\
\hline 1992 & 140. & 840 & 15 & 90 & 600 & 3,600 & - & - & 28 & 168 & 221 & 1,326 & 6,024 & 1,004 \\
\hline 1993 & 100 & 600 & 123 & 738. & 600. & 3,600 & 160. & 960. & 80 & 530 & 405 & 1,900 & 8,328 & 1,468 \\
\hline 1994 & 218 & 1,021 & 255 & 1,172 & 1,113 & 5,226 & 117 & 602. & 761 & 3,885 & 1,446 & 6,798 & 18,704 & 3,910 \\
\hline 1995 & - & & 51 & 375 & - & - & 20 & 140 & 430 & 3,056 & 200 & 1,400 & 4,971 & 701 \\
\hline 1996 & - & - & - & - & - & - & - & - & 300 & 2,130 & 100 & 650 & 2,780 & 400 \\
\hline 1997 & - & - & 40 & 250. & - & - & - & - & 300 & 2,100 & 100 & 650 & 3,000 & 440 \\
\hline 1998 & - & - & - & - & - & - & - & - & 300 & 2,100 & - & - & 2,100 & 300 \\
\hline 1999 & - & - & - & - & - & - & - & - & 300 & 2,100 & - & - & 2,100 & 300 \\
\hline 2000 & - & - & - & - & - & - & - & - & 300 & 2,100 & - & - & 2,100 & 300 \\
\hline 2001 & - & - & - & - & - & - & - & - & 300 & 2,130 & 350 & 2,450 & 4,580 & 650 \\
\hline 2002 & - & - & - & - & - & - & - & - & 300 & 2,145 & 1,000 & 6,200 & 8,345 & 1,300 \\
\hline 2003 & - & - & - & - & - & - & - & - & 360 & 2,340 & 1,000 & 6,200 & 8,540 & 1,360 \\
\hline 2004 & - & - & 63 & 393 & - & - & - & - & 360 & 2,340 & 1,000 & 6,200 & 8,933 & 1,423 \\
\hline 2005 & - & - & 14 & 91 & - & - & - & - & - & - & - & - & 91 & 32 \\
\hline 2007 & - & - & 59 & 374 & - & - & - & - & 190 & 1,320 & 538 & 3,954 & 5,648 & 787 \\
\hline 2008 & - & - & 35 & 238 & - & - & - & - & 279 & 2,132 & 587 & 4,060 & 6,430 & 901 \\
\hline 2009 & - & - & 10 & 65 & - & - & - & - & 300 & 2,130 & 270 & 1,475 & 3,670 & 580 \\
\hline 2010 & - & - & - & - & - & - & - & - & 300 & 1,965 & 300 & 1,350 & 3,315 & 600 \\
\hline 2011 & - & - & - & - & - & - & - & - & 400 & 2,050 & 335 & 2,010 & 4,060 & 735 \\
\hline 2012 & - & - & - & - & - & - & - & - & 366 & 1,504 & 500 & 3,000 & 4,504 & 866 \\
\hline 2013 & - & - & - & - & - & - & - & - & 370 & 1,506 & 275 & 1,590 & 3,096 & 645 \\
\hline Total general & 458 & 2,461 & 683 & 3,786 & 2,313 & 12,426 & 297 & 1,702 & 6,324 & 39,731 & 8,627 & 51,213 & 111,319 & 18,702 \\
\hline
\end{tabular}

Fuente: Evaluaciones Agropecuarias Municipales, Estadísticas Agropecuarias, Secretaria de Agricultura y Desarrollo Económico. Gobernación de Cundinamarca. Elaboración propia

El cultivo de arroz para el periodo de estudio 1992- 2013, se mantuvo estable con un promedio de 6,1 Ton/ Ha, se puede señalar que este rendimiento estuvo dado por la introducción de "avances tecnológicos en todos los procesos desarrollados y no como resultado del incremento del área cultivada" (Méndez Arteaga, y otros, 2011), estos avances tecnológicos responden al mejoramiento del sistema de riego, que en la medida que los factores climáticos fueron afectando los rendimientos, los agricultores usaron la tecnología del sistema de riego como parámetro de adaptación al cambio climático.

Continuando con el análisis, la producción del cultivo de arroz presentó su punto más alto en las variables de producción y área sembrada para el año de 1994 con 18.704 Ton. y 3910 Ha. sembradas, pero paradójicamente en este año, el rendimiento promedio alcanzado en la región fue uno de los más bajos de 4,82 Ton/Ha., como se pude observar en la figura 4, causado por los 
problemas de infraestructura del sistema de riego en la región y unido a esto durante este año se presentaron dificultades en la comercialización y altos costos de producción.

Para el año de 1995, el área sembrada para el total de la provincia decayó en un $82 \%$, dado que los municipios de Agua de Dios, Guataqui, para ese año no sembraron este cultivo, a causa de los altos costos de comercialización y de los fertilizantes y el precio de venta final, de igual forma los municipios de Girador y Tocaima redujeron notablemente su área de siembra para el cultivo de arroz.

En los siguientes años del 1996 a 2000, las expectativas de precio final por productor seguían siendo bajas, comparativamente con los costos de producción sumándole los costos de transporte y los altos precios de arrendamiento de predio. Lo que causó la salida de pequeños agricultores.

Para los años 2001, 2002, 2003 y 2004, el cultivo de arroz riego aumentó la cobertura municipal, pues entró a participar el municipio de Tocaima con 1.000 hectáreas de área sembrada; considerando que el precio final para el productor se incrementó en un $10 \%$ y los costos de producción permanecían estables. En general en nivel de producción y el rendimiento en la provincia del Alto Magdalena se mantuvieron constantes, por tener como característica que siempre se siembra en los mismos terrenos.

En el año 2005, sucede algo atípico la siembra y producción de este cultivo se realizó solo en el municipio de Girardot con 14, hectáreas cosechas y con un total de 91 ton. producidas, con un rendimiento de 6,5 ton/ha, manteniendo así el promedio de la provincia a pesar de ser el único municipio para ese año. 


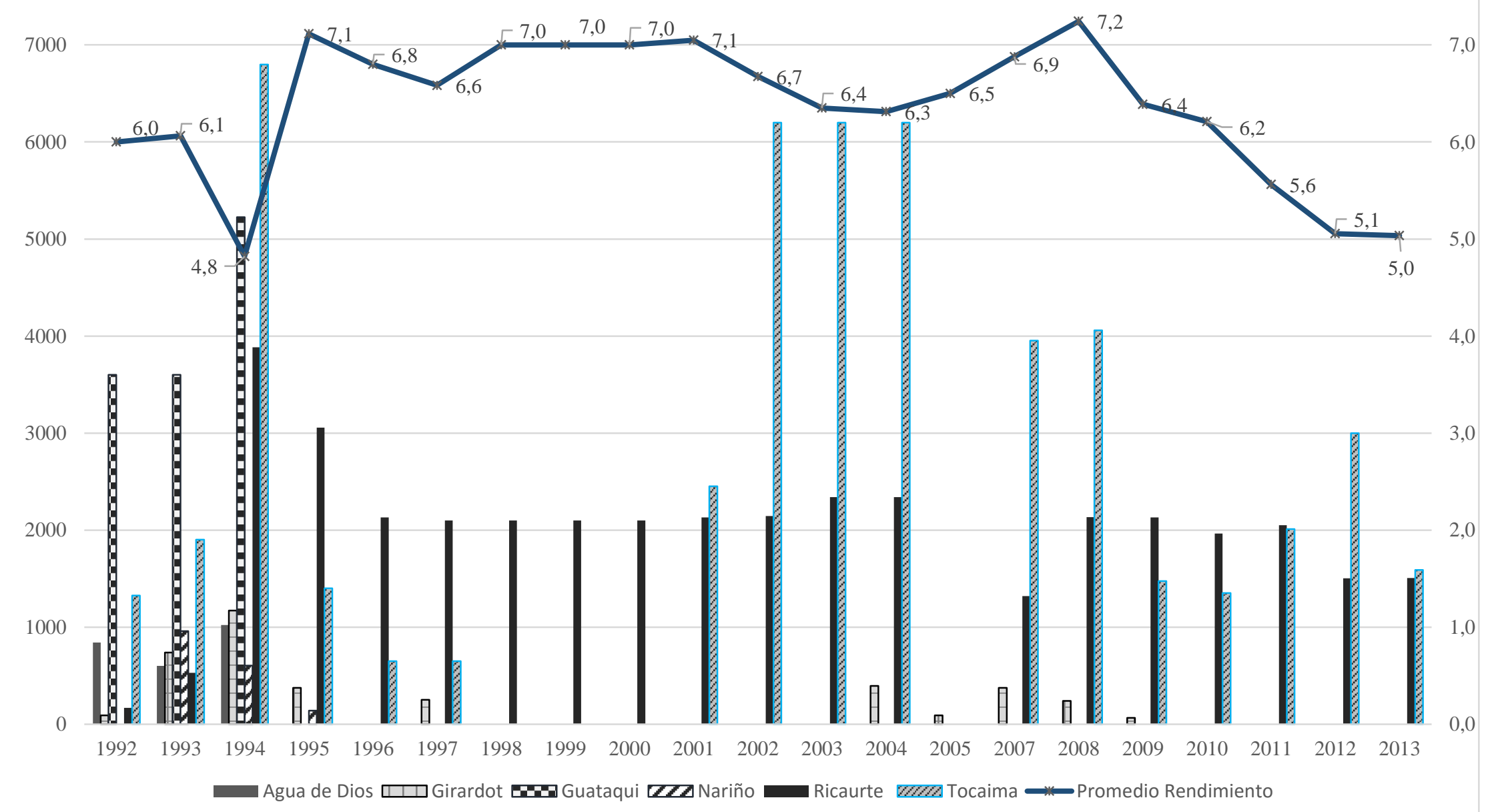

Figura 4. Producción total de Arroz Riego periodo 1992-2013. Redimiendo Promedio provincia Alto Magdalena

Fuente: Evaluaciones Agropecuarias Municipales, Estadísticas Agropecuarias, Secretaria de Agricultura y Desarrollo Económico. Gobernación de Cundinamarca. Elaboración propia 
Para siguientes años 2006-2013, la producción de arroz riego tuvó una tendencia hacia la baja, por factores como poco apoyo crediticio, precio bajo de venta y cambio del uso del suelo en los municipios productores Ricaurte y Tocaima. De igual forma existen variables, exógenas como las variables climáticas y proliferación de plagas, que afectan los rendimientos de los cultivos.

\subsection{Algodón.}

El cultivo de algodón se siembra en los municipios de Agua de Dios con un 7\%, Girardot, $20 \%$, Guataqui, $1 \%$, Nariño $15 \%$, Nilo $2 \%$, Ricaurte $48 \%$ y Tocaima con $6 \%$. Como se puede observar en la figura 5, este cultivo tiene poca trascendencia en la provincia del Alto Magdalena con una producción total de 29.495.81 toneladas durante el periodo de análisis. Para el año de 1995, presentó una fuerte disminución, en cuanto al área cosechada, pues el único municipio que produjo en ese año fue el municipio de Girardot, reflejando una fuerte decaída de la producción y por ende en el rendimiento del cultivo, ocasionado por el fuerte verano y el bajo precio al productor, según datos suministrado por las estadísticas agropecuarias del departamento de Cundinamarca (volumen 14). 


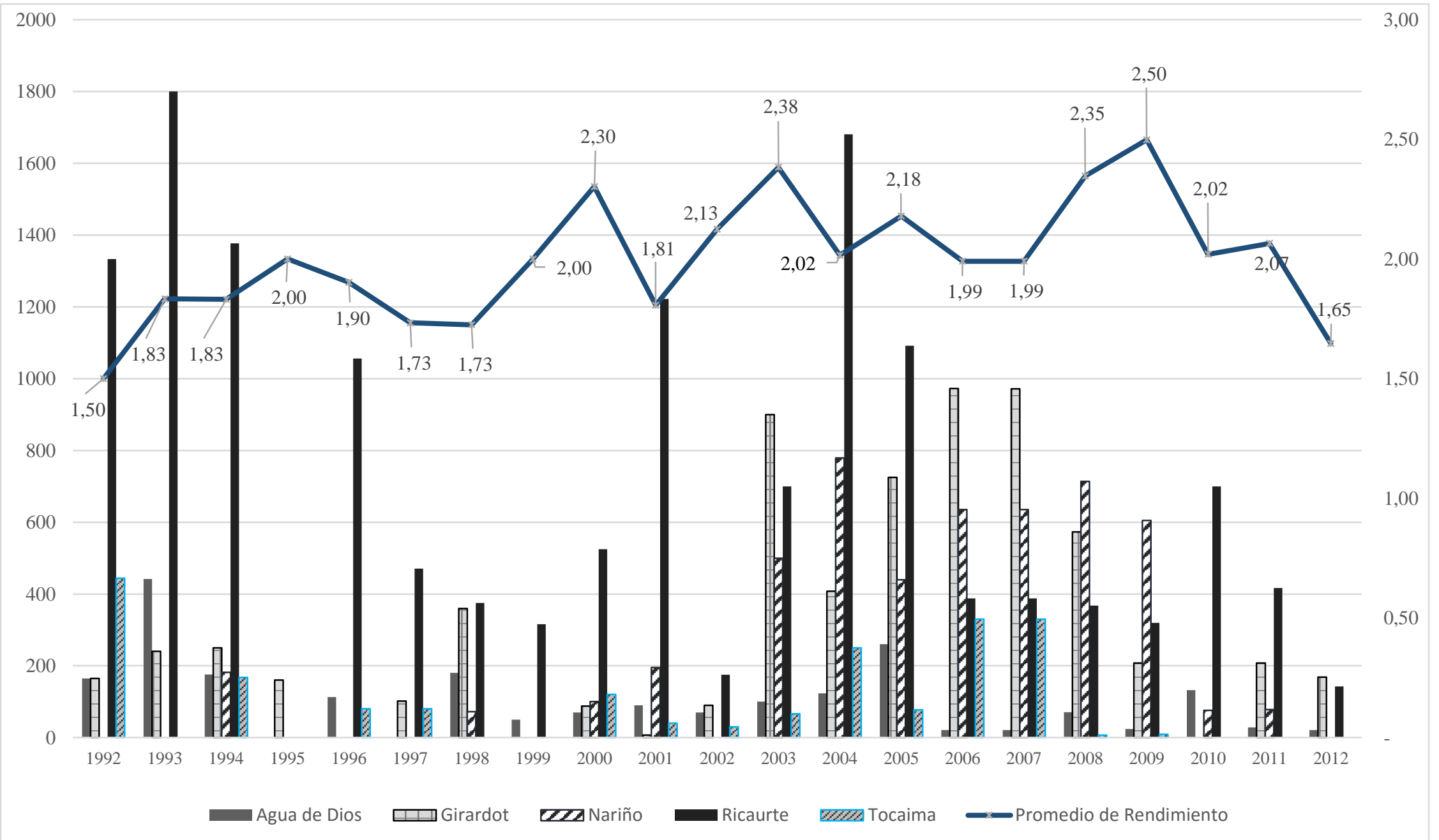

Figura 5. Producción total de algodón periodo 1992-2013. Redimiendo Promedio provincia Alto Magdalena

Fuente: Evaluaciones Agropecuarias Municipales, Estadísticas Agropecuarias, Secretaria de Agricultura y Desarrollo Económico. Gobernación de Cundinamarca. Elaboración propia 
Siguiendo con el análisis, para los años de la década de los 90, el cultivo de algodón no tuvo unos buenos rendimientos, pues estos fueron inferiores a 2, lo que significó que por cada hectárea sembrada se recogía en promedio 1,74 toneladas de algodón, convirtiendo este cultivo poco rentable para los agricultores. En el año de 1999 se presenta otra gran caída en términos de área sembrada, pues lo únicos municipios que decidieron sembrar fueron los municipios de Agua de Dios y Ricaurte, esta decisión tomada por parte de los agricultores de la provincia fue causada por la presencia del fenómeno del niño en la provincia en el año de anterior 1998, lo que hizo que las expectativas de siembra y de producción para el periodo el siguiente cambiaran, decayendo la producción en - 62,92\%.

Para el año 2000 el cultivo tiene un incremento en la producción del 146,72\%, en comparativo con 1999 y aumento del rendimiento del 25\%; en cuanto al año el 2001 sigue con la tendencia alcista en área sembrada y producción con un aumento del 72,09\% con respecto al año 2000, pero debido a la disminución del régimen de lluvias, el rendimiento por hectárea decayó en 20\%. En el año 2002 las expectativas frente al clima eran negativas lo que hizo que se contrajera el área de sembrada, como resultado de esto la producción se redujo en un 76,51\%

Los años 2003 y 2004 representaron los años con mayor crecimiento en la producción de este cultivo produciéndose 2.266 ton y 3241 ton respectivamente, "debido a los acuerdos de comercialización y clima óptimo” (Gobernación de Cundinamarca, 2006). Estas medidas condujeron a que los agricultores de la provincia se vieran incentivados a sembrar este cultivo generando la participación de todos municipios cultivadores para estos dos años.

En los siguientes años se observó un decrecimiento y disminución de la participación en la siembra, producción y recolección de este cultivo; debido los altos costos de producción y disminución de la tasa arancelaria para la fibra de algodón importado y la fuerte competencia de los países asiáticos. 
Otra de las razones por la cual los agricultores de la provincia del Alto Magdalena, no se han visto incentivados para la siembra de este cultivo en los últimos años, es la baja demanda de la fibra de algodón nacional por parte de la industria textil; y el panorama desalentador de que presenta los eslabones de la cadena de algodón, según anunciado por la Confederación Colombiana de Algodón (CONALGADÓN) en la que la industria refleja una gran dependencia a las importaciones, en cuanto la fibra, hilados, tejidos y confecciones.

\section{Función de producción cultivos transitorios provincia del Alto Magdalena}

La función de producción sirve como parámetro para determinar las cantidades de producto que se pueden obtener, con la combinación de diferentes variables entre ellas, área sembrada, insumos y las variables climáticas, estas últimas variables prevalecen de gran importancia, pues estas pueden afectar los rendimientos y el total de la producción y son variables en las que no se tiene una gran inferencia, pero si se pueden generar estrategias para la adaptación ante fenómenos climáticos extremos. En coherencia con la anterior para el desarrollo de este trabajo se realiza la estimación para los cultivos transitorios de sorgo, maíz amarillo tradicional, arroz riego y algodón estos son cultivos representativos y que cuenta con continuidad para el periodo de estudio del este proyecto 1992-2013.

Para el desarrollo de la metodología y estimación de la función de producción, se tuvieron en cuenta las siguientes variables para los cultivos transitorios producidos en la provincia del Alto Magdalena. 
- Índice de precipitación ${ }^{13}$ en la Provincia del Alto Magdalena, que se calculó de manera semestral considerando la información suministrada por las estaciones hidrometeorológicas que se encuentran instaladas en la provincia del Alto Magdalena, proveídas por la Corporación Autónoma Regional de Cundinamarca (CAR)

- Las variables área sembrada y producción, fue suministrada por dos fuentes, para el periodo de los años agrícolas 1992-2006, estos datos se obtuvieron de los documentos publicados anualmente por la Gobernación de Cundinamarca Estadísticas Agropecuarias. Para los años agrícolas 2007-2013, la plataforma Agronet ${ }^{\circledR}$, cuenta de manera digital con los datos. La unidad de medida para el área sembrada es hectáreas (Ha.) y la producción por Toneladas (Ton.)

Siguiendo con los plateado en la metodología, para la estimación de la función de producción, se tuvo en cuenta dos variables climáticas: precipitación y temperatura, sin embargo la variable temperatura, tiene limitantes de información dado que sólo se cuenta con el registro de esta variable en una de las cuatro estaciones hidrometeorológicas ubicadas en la provincia del Alto Magdalena; razón por la cual se debe descartar esta variable para el análisis de la función de producción, no obstante se puede asumir que la variable precipitación tiene una incidencia más marcada al presentar oscilaciones más perceptibles durante el año.

${ }^{13}$ Este índice se calculó siguiendo la metodología realizada por Ruiz Cabarcas, 2012 en el proyecto Análisis del impacto de los Fénomenos El Niño y la Niña en la producción agrícola del departamento del Atlántico 
La Corporación Autónoma Regional de Cundinamarca CAR, cuenta con el centro de monitoreo, en el que se encuentra consignada la información de hidrología, meteorología y del Clima para el departamento de Cundinamarca.

La provincia del Alto Magdalena cuenta con cuatro estaciones hidrometeorológicas, como se puede observar su distribución en la figura 6 y en la tabla 3 se encuentra de forma detallada la ubicación de cada estación.
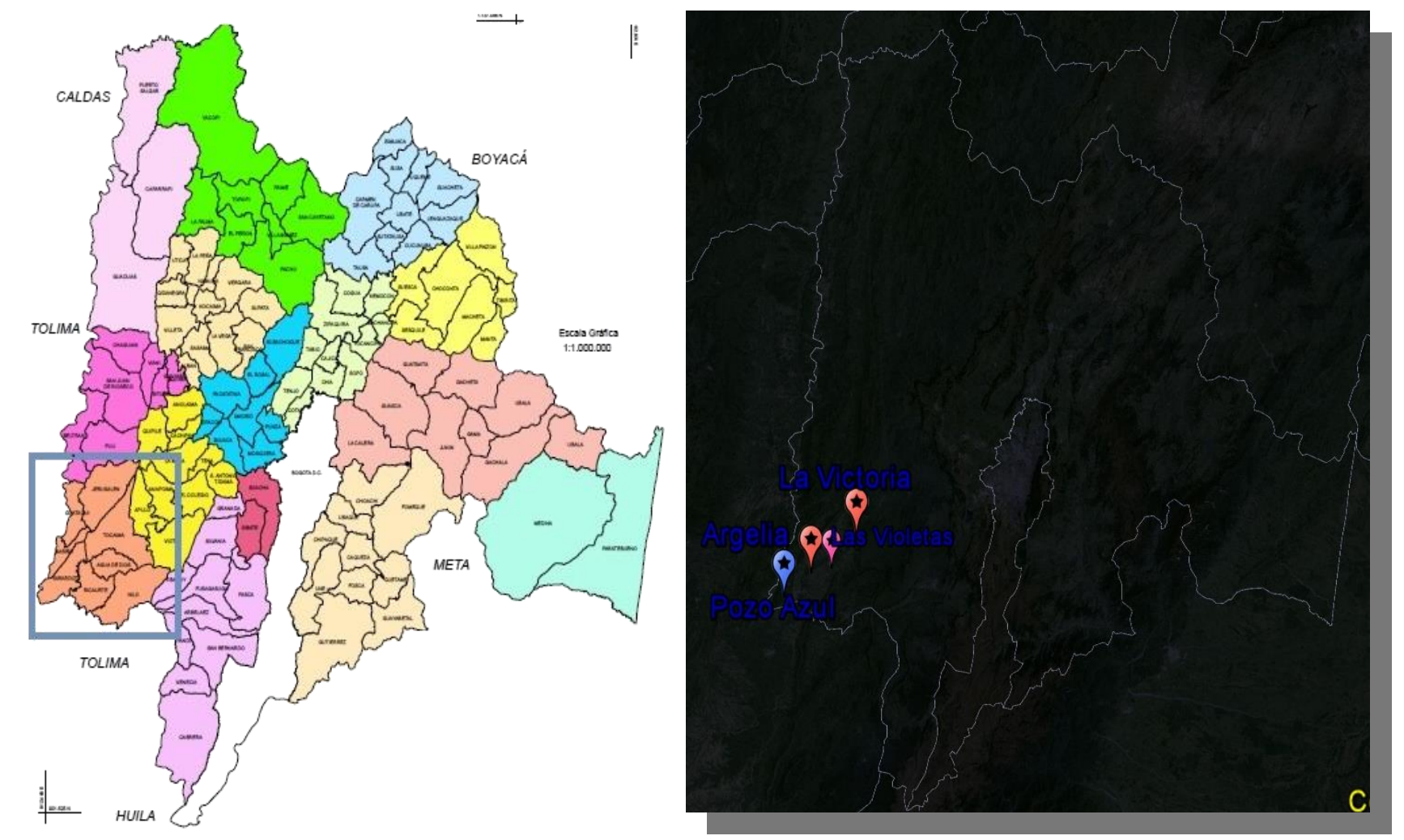

Figura 6. Ubicación Hidrometeorológicas Provincia Alto Magdalena

Fuente: Gobernación de Cundinamarca. Estaciones Hidrometeorológicas Centro de Monitoreo CAR. Elaboración mapa Google Earth 
Tabla 3. Estaciones Hidrometeorológicas de la Provincia del Alto Magdalena

\begin{tabular}{|c|c|c|c|c|c|c|c|c|c|c|c|c|c|c|c|c|c|c|}
\hline \multirow{2}{*}{$\begin{array}{l}\text { Cat. } \\
\text { Código }\end{array}$} & \multirow{2}{*}{ Tipo: } & \multirow{2}{*}{ Cat } & \multirow{2}{*}{ Estación } & \multirow{2}{*}{ Cuenca } & \multirow{2}{*}{ Corriente } & \multirow{2}{*}{ Municipio } & \multicolumn{4}{|c|}{ Latitud } & \multicolumn{4}{|c|}{ Longitud } & \multirow{2}{*}{ ELEV } & \multirow{2}{*}{$\begin{array}{c}\text { NORTE } \\
\text { SICLICA }\end{array}$} & \multirow{2}{*}{$\begin{array}{c}\text { ESTE } \\
\text { SICLICA }\end{array}$} & \multirow{2}{*}{ Fecha Instal. } \\
\hline & & & & & & & Grad & Min & Seg & Dir & Grad & Min & Seg & Dir & & & & \\
\hline 2120181 & Conv. & PG & $\begin{array}{l}\text { Pozo } \\
\text { Azul }\end{array}$ & $\begin{array}{c}\text { R. } \\
\text { Bogotá }\end{array}$ & R. Bogotá & Girardot & 4 & 18 & 1.3 & $\mathrm{~N}$ & 74 & 50 & 12.4 & $\mathrm{~W}$ & 315 & 967019.785 & 916081.326 & 01/04/1989 \\
\hline 2120637 & Conv. & $\mathrm{CO}$ & $\begin{array}{c}\text { Las } \\
\text { Violetas }\end{array}$ & $\begin{array}{c}\text { R. } \\
\text { Bogotá }\end{array}$ & R. Bogotá & $\begin{array}{l}\text { Agua de } \\
\text { Dios }\end{array}$ & 4 & 22 & 41.2 & $\mathrm{~N}$ & 74 & 41 & 17 & $\mathrm{~W}$ & 415 & 975603.122 & 932598.811 & 01/06/1989 \\
\hline 2120640 & Conv. & $\mathrm{CO}$ & $\begin{array}{c}\text { La } \\
\text { Victoria }\end{array}$ & $\begin{array}{c}\text { R. } \\
\text { Bogotá }\end{array}$ & R. Bogotá & Tocaima & 4 & 27 & 58.4 & $\mathrm{~N}$ & 74 & 36 & 32.2 & $\mathrm{~W}$ & 389 & 985333.304 & 941395.771 & 01/12/1986 \\
\hline 2120644 & Conv. & $\mathrm{CP}$ & Argelia & $\begin{array}{c}\text { R. } \\
\text { Bogotá }\end{array}$ & R. Bogotá & Ricaurte & 4 & 21 & 29.3 & $\mathrm{~N}$ & 74 & 45 & 6.5 & $\mathrm{~W}$ & 311 & 973400.481 & 925520.344 & 01/12/1991 \\
\hline
\end{tabular}

Fuente: Estaciones hidrometeorológicas, Centro de Monitoreo Hidrológica y el Clima - Corporación Autónoma Regional. Cundinamarca- CAR. 
Al hacer la revisión de los registros de precipitación mensuales de las estaciones hidrometeorológicas, se presentaron datos faltantes, "ya sea por fallas en los equipos o irregularidades en la operación y mantenimiento de los equipos que operan sin procesos de control estandarizados. De allí que sea necesario establecer una metodología para la imputación de datos faltantes que permita contar con bases de datos adecuadas” Penagos (2014:135), siguiendo la metodología utilizada por Ruiz Cabarcas, (2012) en la que estableció una relación entre los promedios multianuales de dos estaciones, una de referencia y la del datos faltante.

$$
x_{i, j}^{f}=k_{i} * x_{i, j}^{r}
$$

Donde:

$x_{i, j}^{f}=$ Dato faltante (f) en el mes $i$ del año $j$

$k_{i}=$ Coefeciente de la relación entre el mes $i$ de la estación de referencia y la estación con vacío de dato

$x_{i, j}^{r}=$ Dato correspondiente al mes $i$ del año $j$ de la estación en referencia

El calculo del coefeciente $k_{i}$, se realiza de la siguiente manera

$$
k_{i}=\frac{\bar{X}_{i}^{f}}{\bar{X}_{i}^{r}}
$$

Entendiendo que: $\bar{X}_{i}^{f}$ es el promedio multianual para el es $i$ en la estación con vacio de dato en el año $j$ y $\bar{X}_{i}^{r}$, promedio multianual para el mes $i$ en la estación de referencia. Al terminar la imputación de estos datos, se organizarón las series estacionales de precipitación acumulada para el periodo de 1992-2013.

El indice de precipitación se calculo adoptando la metodología de -anomalía de precipitación-, que expresa la variabilidad porcentual de la precipitación en un mes $i$ del año j, con respecto al promedio multianual mes $i$. 


$$
I P=\left[\frac{P_{i}-\bar{P}_{i}}{\bar{P}_{i}}\right]
$$

Donde:

$I P=$ índice de precipitaciones

$P_{i}=$ Precitación del mes $i$

$\bar{P}_{i}=$ Precipitación medía i para los corresponndientes en cada estación hidrometeorológica

\subsection{Especificaciones}

La metodología de panel de datos utilizada para la estimación de las series para el periodo de 1992-2013, permite realizar un análisis desde la dimensión temporal y estructural al incluir a los municipios que componen la región del Alto Magdalena en un periodo determinado y “así capturar la heterogeneidad no observable entre los agentes económicos o de estudio, como también en el tiempo, dado que esta heterogeneidad no se puede detectar ni con estudios de series temporales ni tampoco con los de corte transversal” Mayorga \& Muñoz (2000:3).

Otra razón para elegir dicha metodología tiene que ver con el hecho de que dispone de un mayor número de observaciones y estudiar la dinámica de los procesos de ajuste.

La especificación general del modelo para la región del Alto Magdalena es el siguiente:

$$
Y_{i t}=\alpha_{i t}+\beta_{1} X_{i t} \ldots \beta_{6} X_{i t}+\mu_{i t}(3)
$$

Donde i es el municipio de la región del Alto Magdalena y t es la dimensión en el tiempo.

$Y_{i t}$ es la varaible dependiente producción del cultivo $i$ ésimo municipio en el tiempo t

$\alpha_{i t}$ es el intercepto individual de cada municipio

$\beta_{1}$ es el valor de coeficientes de las varaibles independientes 
$X_{i t}$ es con $k$ variables independientes para el i-ésimo municipio en el tiempo $\mathrm{t}$

$\mu_{i t}$ es un término de error aleatorio.

La estimación de la incidencia entre las variables climáticas y la producción de cultivos transitorios para la provincia del Alto Magdalena del departamento de Cundinamarca, se hace a través de un modelo de panel de efectos fijos, con el objetivo de comprender el análisis dinámico entre las unidades de corte transversal en esta investigación los municipios, para captar las variaciones que se producen a través del tiempo, este modelo permite capturar el efecto individual, "el cual asume que el efecto individual está correlacionado con las variables explicativas" (Labra \& Torrecilla, 2014) separando el término de error del efecto individual. Para tomar la decisión entre el tipo de modelo de estimación, que se debería usar para los cultivos transitorios de la provincia del Alto Magdalena se realizó la validación econométrica del test de Hausman, este compara los $\beta$ obtenidos por medio del estimador de efectos fijos y efectos aleatorios, identificando si las diferencias entre ellos son o no significativas. Y de esta manera decir que tipo de estimador utilizar.

\subsection{Resultados Encontrados}

\subsubsection{Cultivo de Sorgo.}

La función de producción debido a la ley de rendimientos decrecientes es una función no lineal, frente a las variables climáticas ya que llega a un punto máximo, en el cual empieza a decaer y siguiendo la forma de la parábola

$$
Y=\beta_{0}+\beta_{4} P^{2}+\beta_{2} L
$$


Para linealizar las variables se aplicó modelo Log- Log y los resultados obtenidos en el cultivo de Sorgo para la provincia del alto Magdalena, fueron los siguientes como se puede ver en la tabla 4.

Tabla 4. Estimación Modelo Econométrico. Cultivo Sorgo Provincia Alto Magdalena.

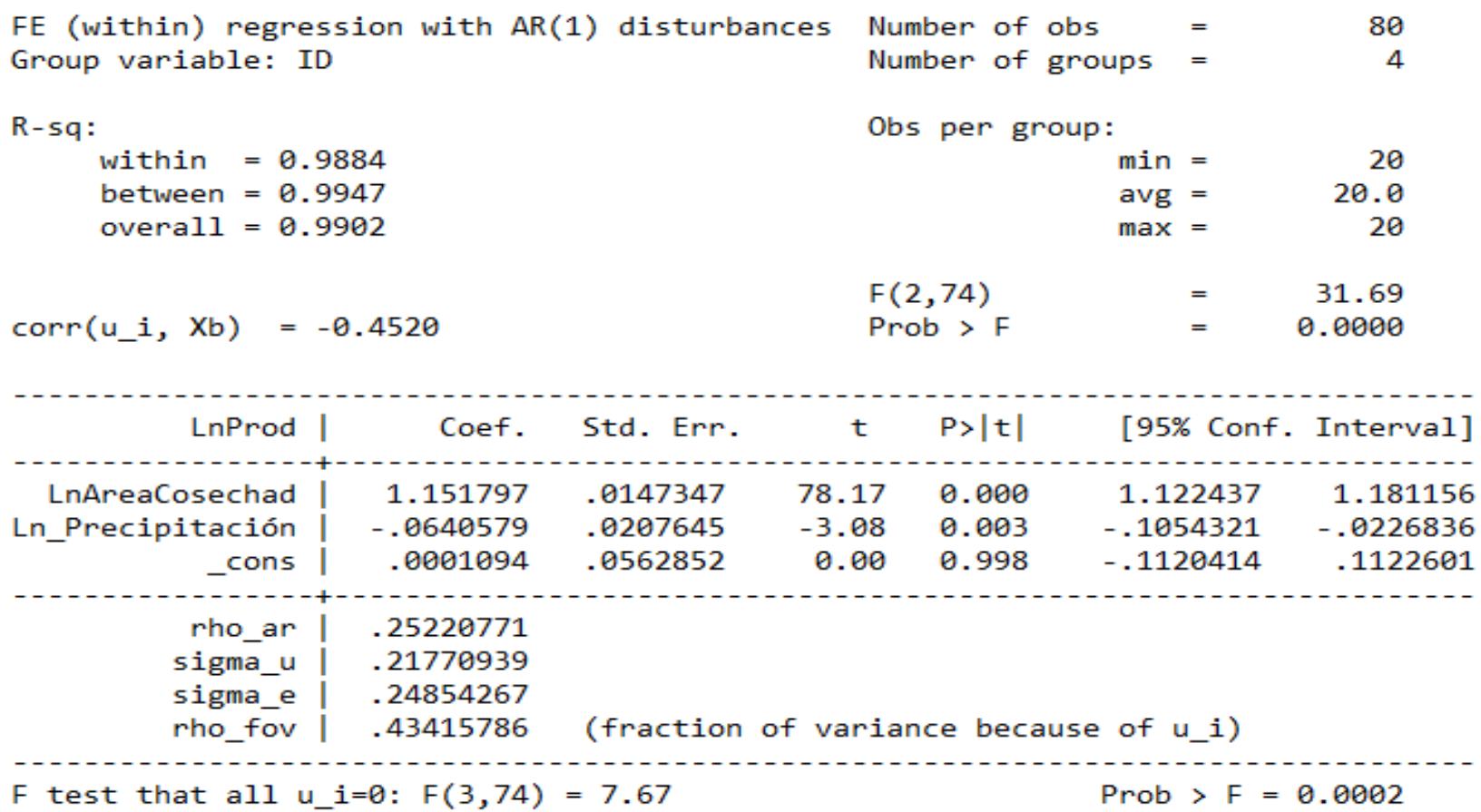

Fuente: Autora. 2015

Para este cultivo contamos con 4 municipios que son, Agua de Dios, Girardot, Nariño y Ricaurte, pues estos municipios son los que cuentan con la vocación para la siembra del cultivo del sorgo, razón por la cual se cuenta con 80 observaciones y cuatro grupos de corte transversal, la bondad del modelo está explicada en un 98, 84\%, como se puede observar en el ítem de observaciones por grupo el mínimo y máximo de observaciones coinciden lo que nos indica que el panel se encuentra balaceado. Existe una significancia conjunta entre los regresores del modelo. Y Finalmente los efectos fijos son significativos, lo que demuestra los efectos individuales de cada municipio frente a las variables independientes. 
Estos resultados permiten comprobar la incidencia de la variable dependiente respecto a las variables independientes de área cosechada y variable precipitación. En el análisis econométrico obtenido, se realizó un estudio de residuales verificando la validez de los supuestos del modelo incluido el análisis de independencia, normalidad y homogeneidad de la varianza. Al examinar el gráfico entre los valores observados y los predichos por el modelo indicó un mal ajuste de los datos, por esta razón las variables fueron previamente transformadas, usando logaritmo natural, para reducir la varianza y homogenizarlos hallando el siguiente modelo: $\mathrm{R}^{2}=98,84 \%$

$$
\begin{gathered}
\ln Y_{i t}=\beta_{1} \ln P^{2}+\beta_{2} \ln A \\
\ln Y_{i t}=-0.064 P^{2}+1.15 A
\end{gathered}
$$

Esta ecuación permitió, encontrar el grado de incidencia de la variable climática precipitaciones respecto a la producción del cultivo de sorgo en la provincia del Alto Magdalena.

Las variables independientes presentan el siguiente comportamiento frente a la variable dependiente; por cada $1 \%$ que varía las precipitaciones la producción del cultivo de sorgo decae 6.4\%, eso demuestra que la producción del cultivo de sorgo es elástica frente a los de la precipitación.

Este resultado comprueba la hipótesis descrita anteriormente, la producción del sorgo tiene una relación directa con la variable climática precipitaciones, contrayendo la producción y por ende los rendimientos del cultivo, afectando los ingresos de los agricultores generando una externalidad negativa en la provincia.

Para ver los resultados del estimador estático más adecuado para el modelo en este caso efectos fijos, se empleó el test de Hausman en el que se compararon los estimadores $\beta$ de efectos aleatorios y efectos fijos, (Ver anexo C) 


\subsubsection{Cultivo de Maíz Amarillo Tradicional}

Siguiendo la metodología de trabajo se obtuvieron los siguientes resultados para el cultivo de maíz amarillo tradicional. Ver tabla 5.

Tabla 5. Estimación Modelo Econométrico. Cultivo Maíz Amarillo Provincia Alto Magdalena.

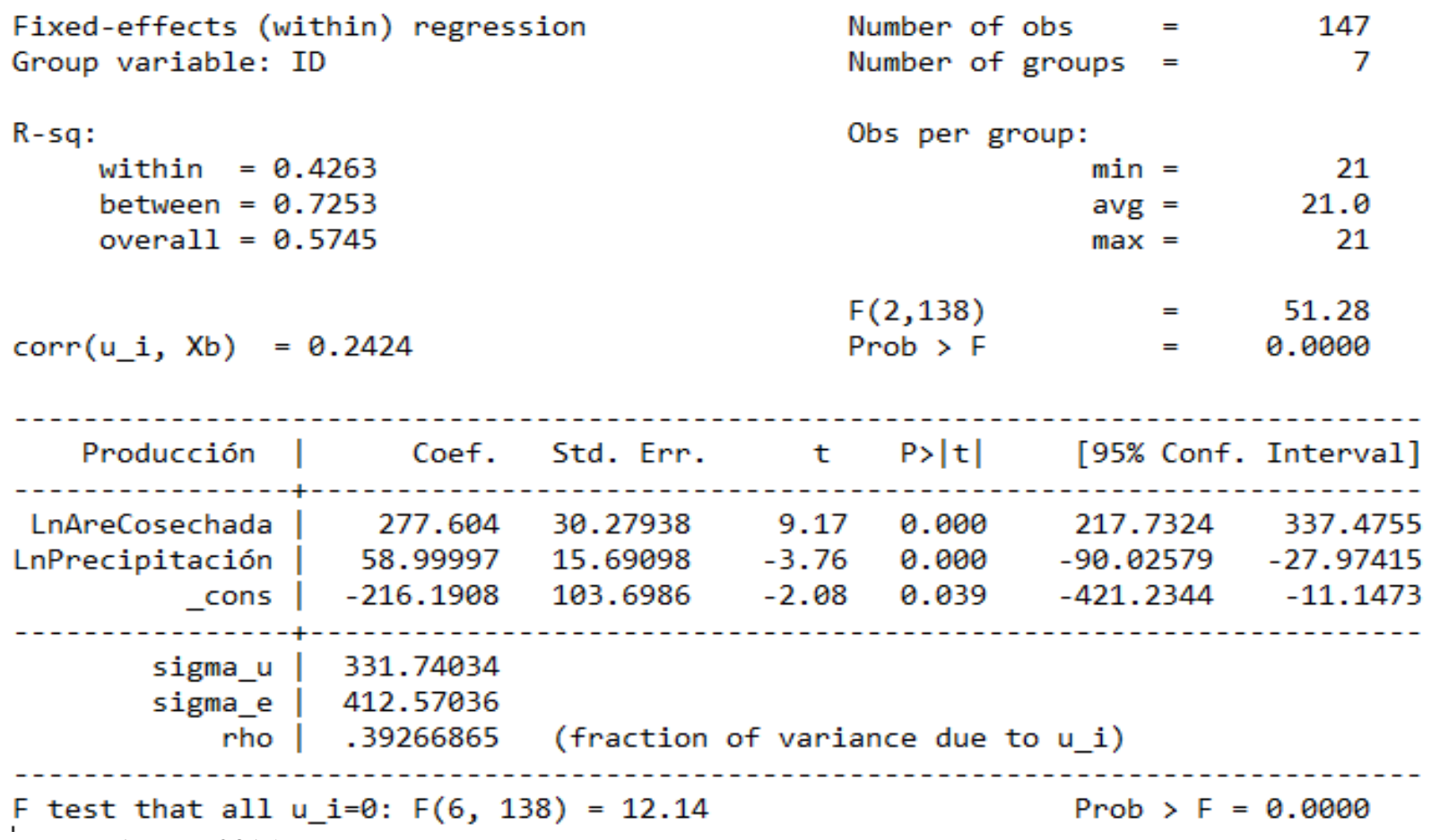

Fuente: Autora. 2015

Las variables explicativas del modelo tienen una mayor incidencia, al aumentar en una hectárea el área cosechada, la producción del cultivo de maíz amarillo aumenta en 277.604 hectáreas, la variable climática de precipitación presenta ser significativa para la producción de este cultivo, siguiendo con el análisis este cultivo tiene presencia en los siete municipios agricultores de cultivo transitorios, Agua de Dios, Girardot, Guataqui, Jerusalén, Nariño, Ricaurte y Tocaima, razón por la cual el panel de datos tiene siete grupos, el modelo es significativo, el panel se encuentra balanceado, y los efectos fijos son estadísticamente significativos. 


\subsubsection{Cultivo de Arroz de Riego}

El cultivo de arroz se encuentra presente en tres municipios que son: Girardot, Ricaurte y Tocaima, razón por la cual se cuenta con tres grupos y 63 observaciones. El panel de datos se encuentra balaceado. Los resultados se pueden observar en la tabla 6.

Tabla 6. Estimación Modelo Econométrico. Cultivo Arroz de Riego Provincia Alto Magdalena.

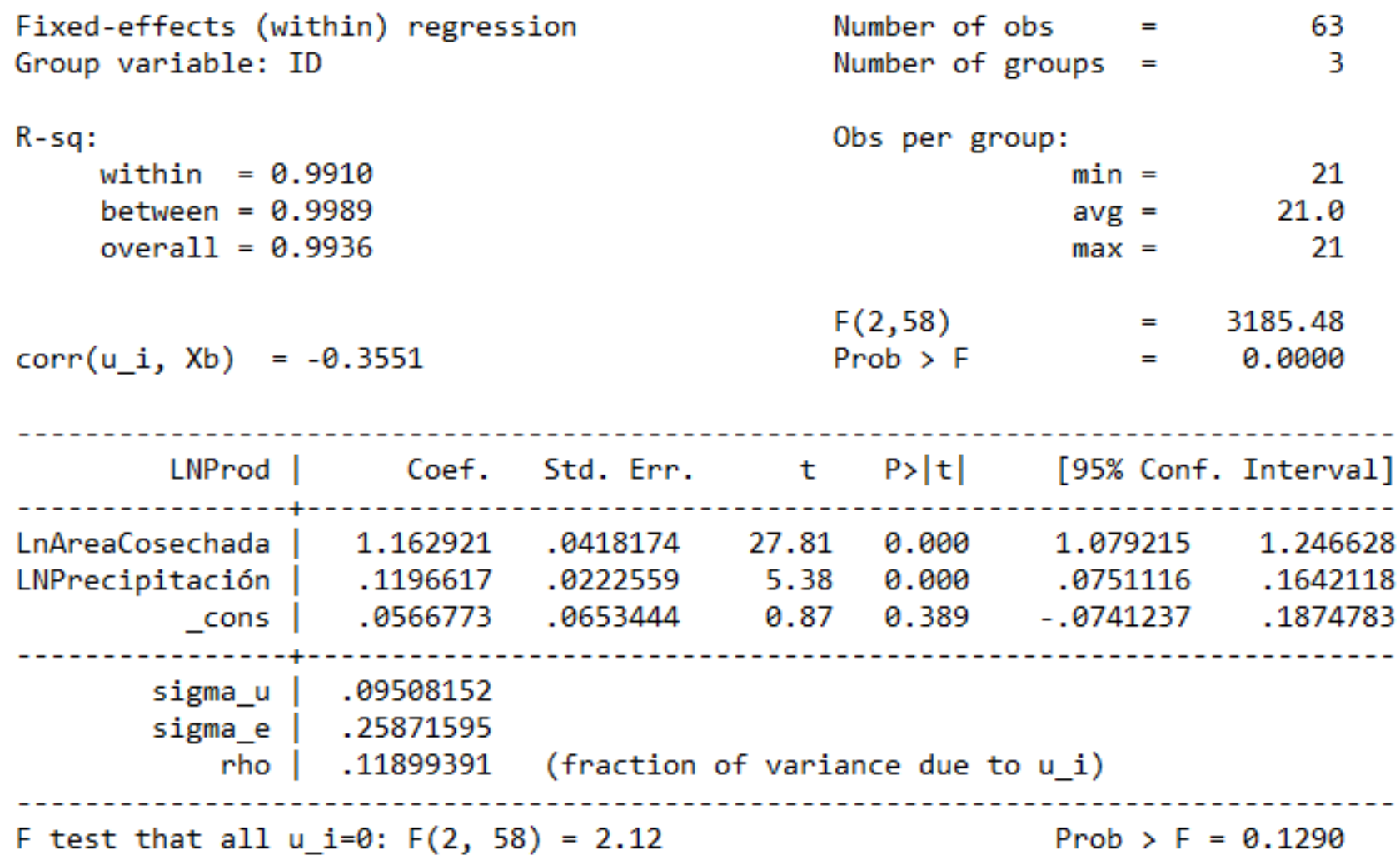

Fuente: Autora. 2015

Los resultados obtenidos para este cultivo cumplen con los signos esperados, las precipitaciones tienen una relación positiva para a producción en el cultivo de arroz de riego, esto es coherente, dado que este cultivo tiene una gran dependencia para su crecimiento de un alto afluente de agua, por cada $1 \%$ que aumente las precipitaciones la producción del cultivo de Arroz de riego aumenta en un $11 \%$ las variables independientes explican a la producción del cultivo de arroz de riego en $99.36 \%$, revisado la probabilidad de F demuestra la significancia del modelo y los efectos fijos son estadísticamente significativo. 


\subsubsection{Cultivo de Algodón}

Este cultivo tiene una particularidad frente a los demás cultivos transitorios en cuanto la estimación econométrica, al aplicar el test de Hauman (ver anexo I) para determinar la significancia entre los estimadores de efectos fijos o efectos aleatorios, arrogo como resultado que el mejor estimador es bajo efectos aleatorios los resultados obtenidos fueron los siguientes que se pueden observar en el tabla 7:

Tabla 7. Estimación Modelo Econométrico. Cultivo Algodón Provincia Alto Magdalena.

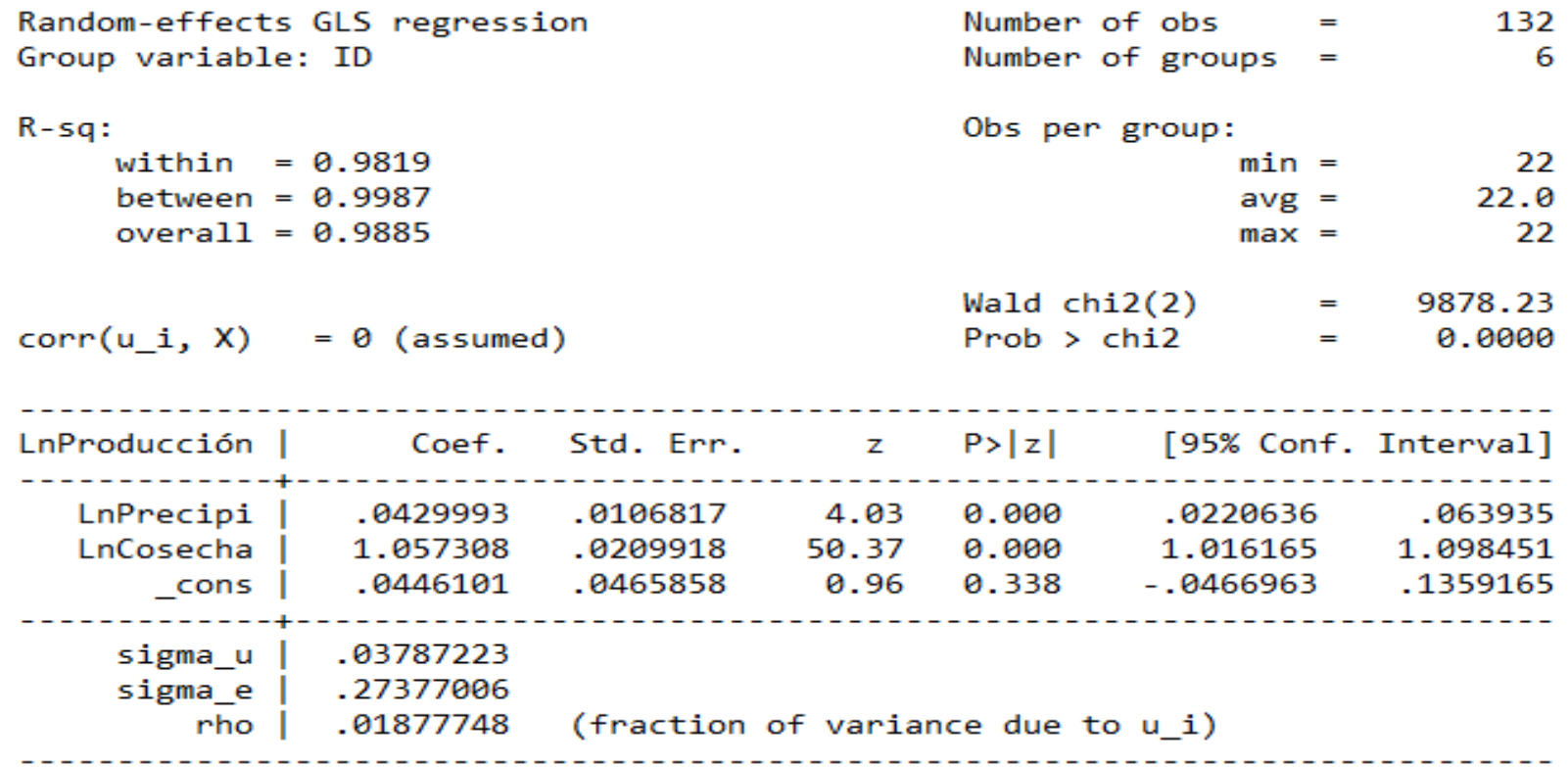

Fuente: Autora. 2015

Los municipios que participan con el cultivo de algodón son Agua de Dios, Girardot, Guataquí, Nariño, Ricaurte y Tocaima. Los coeficientes de bondad de ajuste muestran que los modelos de efectos aleatorios dan una ponderación mayor a la variación de efectos fijos. Se asumen que no existe correlación entre los efectos aleatorios. El test de Wald, valida la significancia de las variables independientes. El Rho nos explica la proporción de los efectos conjuntos que provienen de los efectos individuales. El 1,8\% del error compuesto del modelo se debe a efectos individuales. 


\section{Propuesta Política de Intervención}

Para lograr la aplicación y puesta en marcha de las estrategias de adaptación al cambio climático de los agricultores, es importante un fortalecimiento de las instituciones que participan en el sector de la provincia del Alto Magdalena, que permitan el desarrollo, con una mayor contribución teniendo en cuenta su naturaleza y sus funciones, logrando una complementariedad que se verá reflejado en un sector más competitivo a nivel de provincia y departamental.

La institucionalidad del sector agrícola en la provincia está determinada por la intervención de entidades en tres categorías la figura 7 muestra como estas emergen al desarrollo del sector agrícola:

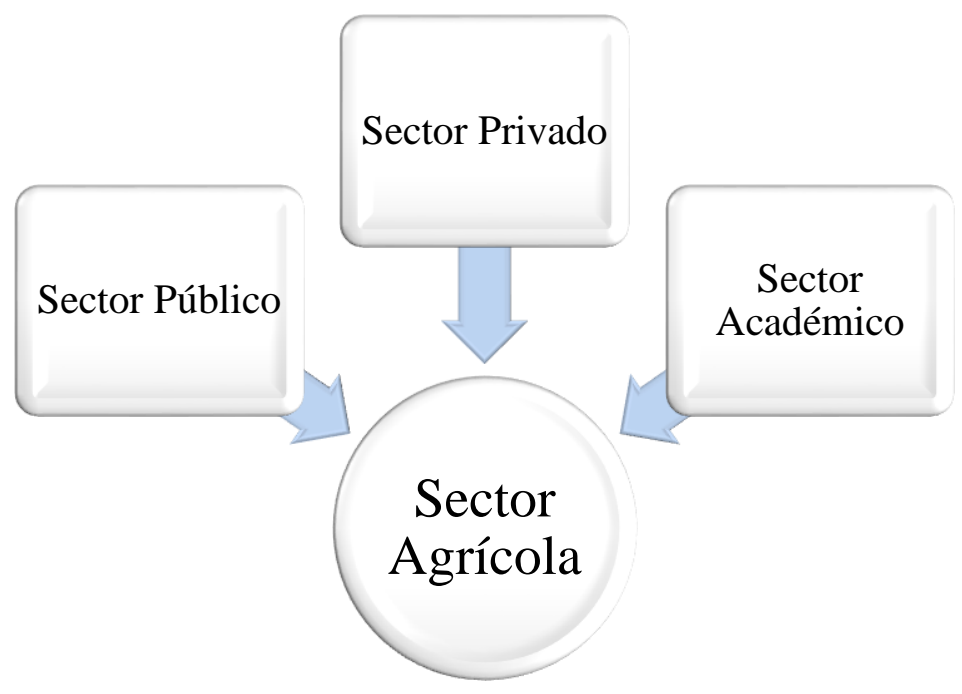

Figura 7. Instituciones del Sector Agrícola

Fuente Autora. 2015

1. Sector público cuenta con la Secretaria de Agricultura adscrita a la Gobernación de Cundinamarca, que, a su vez, está secretaria tiene la oficina asesora Unidad Regional de Planificación Agropecuaria "URPA", la cual es la encargada de "establecer un sistema de información agropecuario adecuado, que permita a los entes públicos y privados una eficiente toma de decisiones.” (Gobernación de Cundinamarca, 2015) 
como su función primordial; este sistema de información es alimentado a través de la consolidación de las Evaluaciones Agropecuarias Municipales " $E V A$ ” cuyo objetivo es recoger la información de la oferta productiva agropecuaria y acuícola a nivel municipal, estas evaluaciones son diligenciadas por las Unidades Municipales de Asistencia Técnica Agropecuaria "UMATA”, cada municipio de la Provincia cuenta con oficina de estas unidades. Finalmente, en materia ambiental se cuenta con la institución Corporación Autónoma Regional “CAR” cuyo objetivo es la ejecución de las políticas, planes, programas y proyectos sobre medio ambiente y recursos naturales no renovables.

2. Sector Privado: Los productores de cereales y algodón cuentan con la agremiación AGRO. S.A. para su comercialización excepto para el cultivo de maíz amarillo. Esta agremiación debe reportar la información de cantidades vendidas, costos de producción, precio final de venta para el cultivo de algodón a la Confederación Colombiana de Algodón- "Conalgodón” y FENALCE

3. Sector académico: En la provincia se cuenta con la oferta educativa en la educación superior con cinco universidades y del Servicio Nacional de Aprendizaje (SENA), el $66 \%$ son instituciones públicas.

Lo que se pretende con esta propuesta de política de intervención es lograr la coordinación y ejecución de programas, acciones y planes, entre cada una de las categorías anteriormente descritas para lograr competitividad del sector agrícola en la provincia del Alto Magdalena. Pues si bien existen estas instituciones y la comunidad del sector agrícola tiene aceptación hacia ellas, estas instituciones no tienen una credibilidad marcada y canales de comunicación; por lo tanto, no hay una disposición en el corto plazo para obtener acciones 
conjuntas que permitan desarrollar el potencial inicial para la producción de cultivos transitorios. Que siguiendo las figuras 2, 3, 4 y 5 del capítulo 10, en la que se evidencia que en los primeros años del periodo de estudio existía unos niveles de producción más altos, pero esto ha venido cambiando en la medida que variables exógenas, como política comercial, cambio de uso de suelo en la provincia y decisiones de índole político, hicieron que las entidades perdieran su institucionalidad convirtiéndola en entidades frágiles que no cuentan con herramientas para incrementar la competitividad.

Con el escenario anterior, es importante hacer una transformación de las instituciones públicas a nivel de provincia, que permita la participación y coordinación de manera eficaz y eficiente, de acuerdo con las condiciones del sector agrícola de la provincia del Alto Magdalena. Dado que se tienen claramente definidos los objetivos estratégicos a nivel departamental para el desarrollo del sector que son: 1 . El acompañamiento en los procesos productivos y de transformación, 2. establecer estrategias para la creación de clima de negocios adecuado en la que se tenga transferencia de tecnología y 3. La articulación de los eslabones de las cadenas productivas para alcanzar la competitividad del sector. A nivel provincial estos objetivos no están claramente desarrollados bajo una planeación estratégica ni bajo procesos sistémicos en las que se involucren el desarrollo de actividades conjuntas entre las instituciones públicas

En coherencia con lo anterior, esta propuesta de intervención propone que la institucionalidad pública debe enfrentarse a un proceso paulatino y continuo de modernización, bajo los siguientes ejes: 1. Visión integral y sistémica, que permita la provisión de bienes y servicios para la producción, generando mecanismos de cooperación entre las instituciones; 2. Alineamiento interinstitucional, este eje es formulado con el objetivo de que exista una estrecha relación público-privada, en la que las agremiaciones como AGRO S.A. se empoderen en el 
acompañamiento de los procesos productivos y de comercialización para lograr una menor perdida de la eficiencia en el mercado de los cultivos transitorios. 3. Transferencia de la información, con la inclusión de tecnologías para el cumplimiento de la función sustantiva la URPA, que es, "establecer un sistema de información agropecuario adecuado" (Gobernación de Cundinamarca, 2015), se hace necesario organizar la información a nivel municipal, para consolidar de manera agregada a nivel de provincia y departamental; mejorar el acceso al sistema de información y actualización de manera desagregada para lograr el desarrollo de investigaciones y haya un involucramiento de la academia para logar la transferencia de conocimiento. 4. Identificación de Cadenas, a nivel de provincia no se ha determinado las cadenas productivas de los cultivos transitorios, en una alianza público privada en la que la agremiación AGRO S.A. aporta su conocimiento sobre el mercado de los cereales y el algodón a nivel local, las Unidades Técnicas "UMATA" hace su contribución en los insumos técnicos para el mejoramiento en términos de rendimiento del cultivo y la academia a través de procesos de investigación. Se puede lograr la identificación y desarrollo de las cadenas productivas de los cultivos transitorios de la provincia del Alto Magdalena.

Las instituciones a nivel de la provincia tienen el reto de lograr un desarrollo de sector agrícola desde un punto de vista competitivo, sostenible, equitativo e incluyente. Para conseguir este desarrollo se deben lograr: Elevar la competitividad: Para la inserción en los mercados inicialmente a nivel interno, ajustar las condiciones de financiamiento y seguros de acuerdo a las características productivas del cultivo, incorporar las tecnologías de la información y la comunicación suministradas a nivel público que permitan a los agentes la toma decisiones en los procesos de siembra y producción. Aumentar la inversión en infraestructura para aumentar la disponibilidad. 
Desarrollo de la innovación e inserción tecnológica. Con el fin de optimizar el aprovechamiento de los recursos productivos y aumentar su potencial, generar sistemas de alerta temprana para tener una producción competitiva en un contexto adverso frente a la variabilidad climática. El desarrollo de la innovación también está encadenado en el capital humano, haciendo importante que los agricultores desarrollen sus capacidades de dirección y toma de decisiones para lograr procesos de innovación.

Gestión de Territorios Rurales las características propias de la provincia del Alto Magdalena, tienen una tendencia marcada en zonas rurales y el sector agrícola está compuesto por pequeños productores que deben ser incorporados a los circuitos comerciales, en condiciones competitivas, equitativas socialmente y ambientalmente sostenibles.

Adaptación al Cambio Climático: Prevenir los riegos asociados a la variabilidad climática, con la inclusión de sistema de alertas tempranas que permitan dar una adecuada atención y manejo de ocurrencia de desastres. Y adaptar los procesos productivos a las nuevas condiciones climáticas, con el desarrollo de nuevas opciones de producción, nuevas prácticas de cultivos que permitan recuperar el potencial genético.

Siguiendo con el objetivo propuesto de la investigación y la evidencia arrogada sobre la incidencia de las variables climáticas en la producción de los cultivos transitorios en la provincia del Alto Magdalena, se han diseñado estrategias de adaptación al cambio climático, para promover los esfuerzos intersectoriales para mitigar el impacto y mejorar la adaptación, ya que la variabilidad climática se considera un fenómeno global que afecta directamente a la producción agrícola y otras actividades económicas, estas estrategias están pensadas para favorecer la sostenibilidad de los procesos productivos para lograr una inserción en los mercados interno a nivel departamental y nacional. 


\subsection{Estrategias de Adaptación}

La adaptación a las variaciones climáticas y a la presencia de eventos climáticos extremos, se puede convertir en una estrategia de competitividad en los territorios y en las regiones; ya que estos cambios afectan directamente la producción y aumentan sus costos. Ahora, si los agricultores están preparados y conocen de antemano la incidencia de estos factores meteorológicos en sus cultivos, la generación de un sistema de alarmas tempranas podría contribuir con su desarrollo.

Los procesos de adaptación se conocen como el "ajuste de los sistemas naturales o humanos en respuesta de los estímulos climáticos reales o esperados" Andrade Castañeda, y otros (2013:35); es así como las prácticas agrícolas permiten la identificación de condiciones cambiantes a los efectos climáticos, para la minimización de las pérdidas.

Luego, las estrategias de adaptación deben ser flexibles e integradas con las comunidades, pues es indispensable "vincular la participación comunitaria en el proceso de planificación y definición de medidas de adaptación más efectivas y duraderas, ya que son las comunidades las que mejor conocen sus características y necesidades" Departamento Nacional de Planeación DNP (2012:15). Lo que permite no solo una identificación de sus factores de riesgo sino un menor grado de sensibilidad frente a los fenómenos climáticos.

En ese sentido, existen tres tipos de adaptación: 1. Anticipador, 2. Autónoma y 3. Planificada; este último es el propuesto en el $\mathrm{PNACC}^{14}$ que es el resultado de una política nacional y en coherencia con el plan de desarrollo nacional, que permite entender que los entes gubernamentales tienen una comprensión de que las condiciones climáticas han cambiado y que se requieren medidas en todos los niveles: nacional, departamental y municipal; es así que en el ámbito departamental se cuenta con un programa llamado Gestión del riesgo y adaptación al

\footnotetext{
${ }^{14}$ Plan Nacional de Adaptación al Cambio Climático.
} 
cambio climático y variabilidad climática, adscrita a la Secretaría de Agricultura de la Gobernación de Cundinamarca.

Las estrategias de adaptación planteadas para la provincia del Alto Magdalena, se encuentra bajo el marco del Plan Nacional de Adaptación al Cambio Climático (PNACC) que son las siguientes: Concientizar a las comunidades sobre el cambio climático, generar información y conocimiento para medir el riesgo, planificar el uso del territorio, implementar proyectos y, por último, fortalecer la capacidad de reacción, como se puede observar en la figura 8.

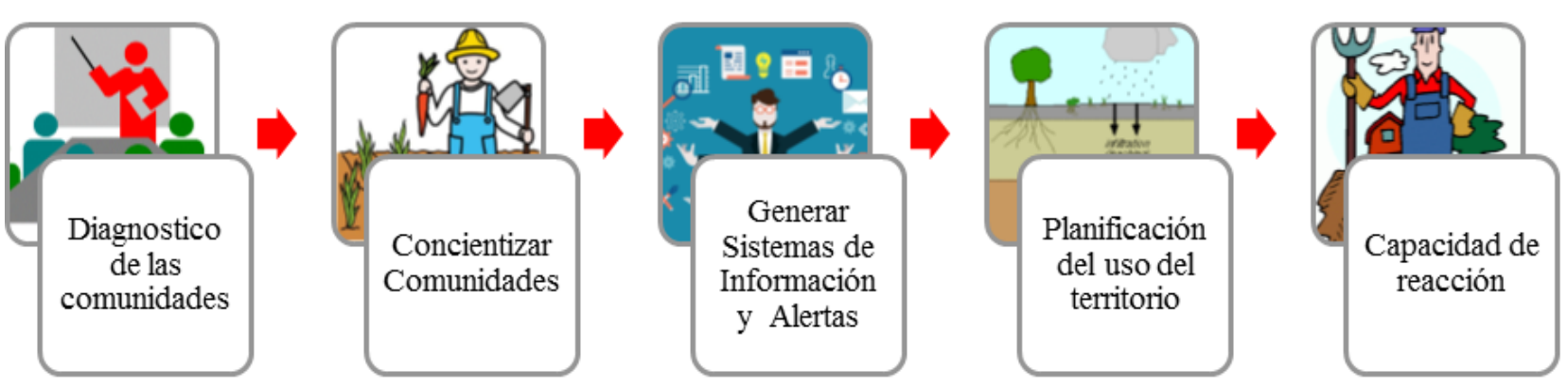

Figura 8. Proceso de Adaptación.

Fuente: PNACC.

Retomando las líneas estratégicas propuestas por el PNACC -que inicia con un proceso de concientización de las comunidades-, conviene validar su importancia, al contribuir con el incremento de la capacidad adaptativa a los efectos adversos que generan el cambio climático y la presencia de fenómenos extremos (ENOS); pues permite que las comunidades, los sectores afectados y entes territoriales generen canales de comunicación en pro de obtener la información requerida sobre su afectación, así como el potencial surgimiento de sistemas de alerta. Lo que enriquece todavía más el proceso, pues al conocer qué comunidades y territorios son más vulnerables a estos cambios, es posible la planificación del territorio teniendo en cuenta las 
variables climáticas; componentes que se ven reflejados en la capacidad de reacción de la comunidad

Así pues, las razones por la que se debe promover la adaptación al cambio climático se da por la estrecha relación que existe entre el clima, la productividad y el desarrollo regional, como se evidencia en los resultados encontrados en este trabajo; en la que las variables climáticas afectan de manera negativa la producción en los cultivos transitorios de la provincia del Alto Magdalena. El proceso para aplicación de la estrategia se encuentra en la figura 9 y la sistematización de las estrategias en tabla 8: 


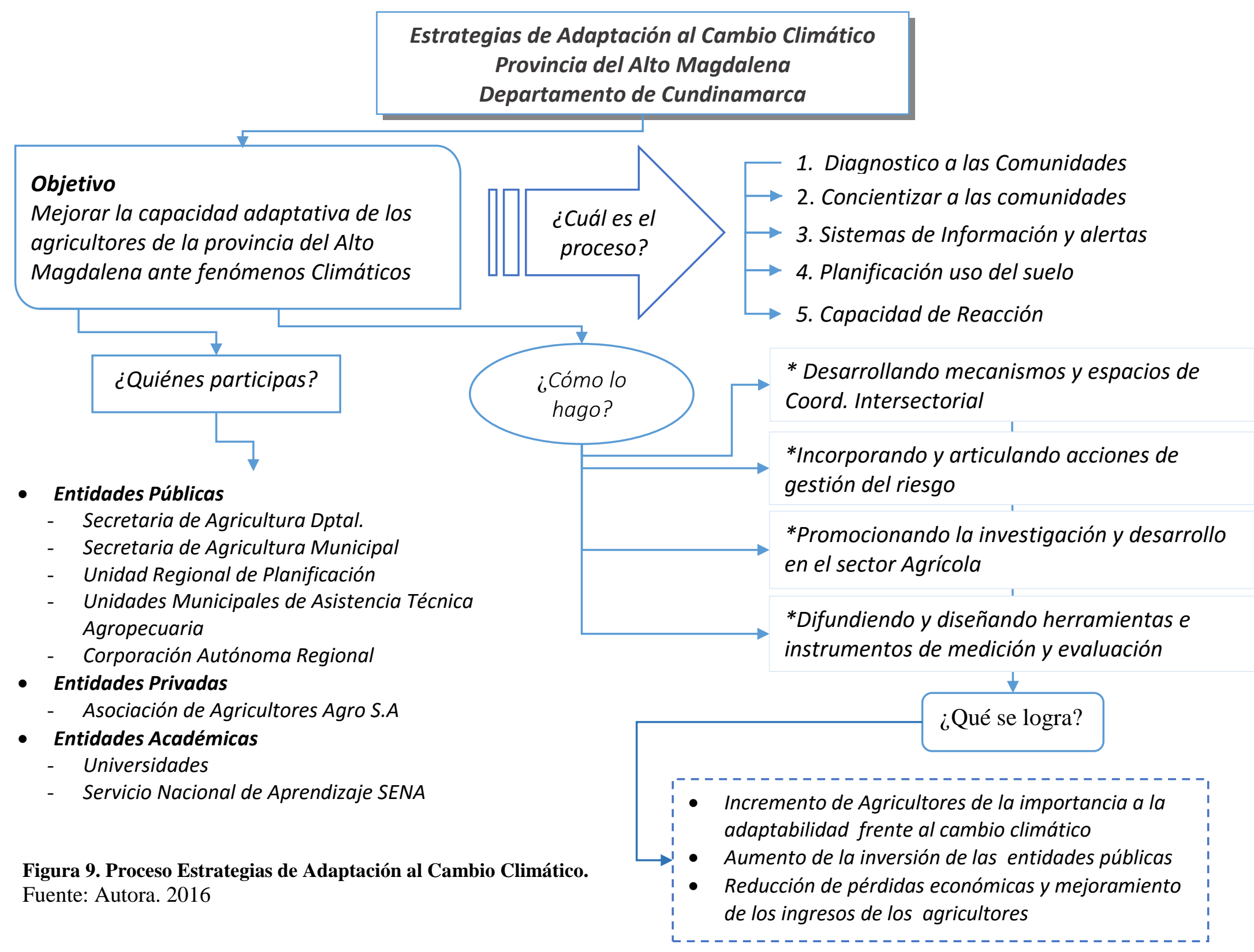


Tabla 8 Estrategias de adaptación al Cambio Climático

\begin{tabular}{|c|c|c|c|c|}
\hline $\begin{array}{l}\text { Línea } \\
\text { de } \\
\text { Acción }\end{array}$ & Población Objetivo & Instrumentos & Indicador & Resultado \\
\hline 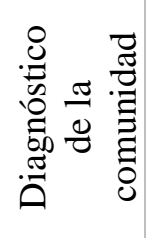 & $\begin{array}{l}\text { Comunidad de } \\
\text { agricultores en la } \\
\text { provincia del Alto } \\
\text { Magdalena. }\end{array}$ & $\begin{array}{l}\text { Encuestas } \\
\text { Listas de verificación. }\end{array}$ & $\begin{array}{l}\text { (No. de personas } \\
\text { encuestas / No. total de } \\
\text { persona de la población } \\
\text { objetivo) } * 100 .\end{array}$ & $\begin{array}{l}\text { Diagnóstico } \\
\text { inicial de la } \\
\text { comunidad frente } \\
\text { a las variables } \\
\text { climáticas. }\end{array}$ \\
\hline \multirow{2}{*}{ 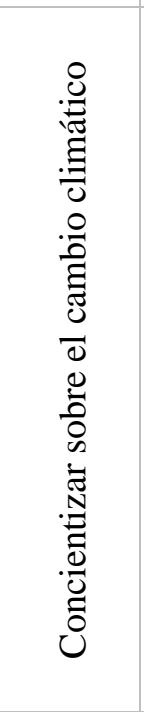 } & \multirow{2}{*}{$\begin{array}{l}\text { Comunidad de } \\
\text { agricultores de } \\
\text { Cultivos Transitorios } \\
\text { en la región del Alto } \\
\text { Magdalena. } \\
\text { Entes territoriales y } \\
\text { entidades de control } \\
\text { de la región del Alto } \\
\text { Magdalena. }\end{array}$} & \multirow{2}{*}{$\begin{array}{l}\text { Campañas de formación y } \\
\text { educación a la comunidad } \\
\text { en la generación de } \\
\text { información de } \\
\text { producción de las } \\
\text { cosechas, costos e } \\
\text { información actualizada } \\
\text { de las estaciones } \\
\text { meteorológicas por medio } \\
\text { de la coordinación de los } \\
\text { entes territoriales y } \\
\text { entidades de control a } \\
\text { través de: } \\
\text { Conferencias, plegables, } \\
\text { trabajos grupales, talleres } \\
\text { físicos y capacitaciones. }\end{array}$} & $\begin{array}{l}\text { (No, de personas } \\
\text { capacitadas / No, total de } \\
\text { personas de la población } \\
\text { objetivo) } * 100 \text {. }\end{array}$ & $\begin{array}{l}\text { Aceptación de la } \\
\text { comunidad } \\
\text { capacitada en los } \\
\text { procesos de } \\
\text { formación. }\end{array}$ \\
\hline & & & $\begin{array}{l}\text { No, de capacitaciones } \\
\text { realizadas / total de } \\
\text { capacitaciones } \\
\text { programas }) * 100 .\end{array}$ & $\begin{array}{l}\text { Cumplimiento del } \\
\text { programa. }\end{array}$ \\
\hline 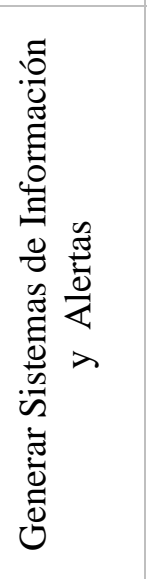 & $\begin{array}{l}\text { Comunidad de } \\
\text { agricultores de } \\
\text { cultivos transitorios } \\
\text { en la región del Alto } \\
\text { Magdalena. } \\
\text { Entes territoriales y } \\
\text { entidades de control } \\
\text { de la región del Alto } \\
\text { Magdalena. }\end{array}$ & $\begin{array}{l}\text { Formatos de recolección } \\
\text { de información total de } \\
\text { producción, total de áreas } \\
\text { cosechadas y áreas } \\
\text { sembradas. } \\
\text { Informes mensuales de } \\
\text { las estaciones } \\
\text { meteorológicas de la } \\
\text { región del Alto } \\
\text { Magdalena. } \\
\text { Modelo de Gestión del } \\
\text { Riesgo frente a las } \\
\text { variables climáticas. }\end{array}$ & $\begin{array}{l}\text { (No, de agricultores que } \\
\text { diligencia el formato/ No, } \\
\text { total de Agricultores de la } \\
\text { provincia del Alto } \\
\text { Magdalena) } * 100 . \\
\text { (No, de informes } \\
\text { mensuales de la } \\
\text { estaciones meteorológicas } \\
\text { / Total de estaciones } \\
\text { meteorológicas) * } 100 \\
\text { Elaboración del Modelo } \\
\text { de Gestión del Riesgo. }\end{array}$ & $\begin{array}{l}\text { Bases de datos } \\
\text { actualizadas para } \\
\text { la generación de } \\
\text { sistemas de } \\
\text { información. }\end{array}$ \\
\hline 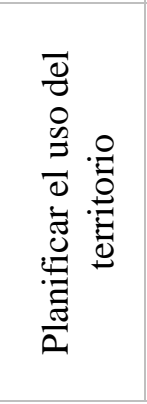 & $\begin{array}{l}\text { Comunidad de } \\
\text { agricultores de } \\
\text { cultivos transitorios } \\
\text { en la región del Alto } \\
\text { Magdalena. } \\
\text { Entes territoriales y } \\
\text { entidades de control } \\
\text { de la región del Alto } \\
\text { Magdalena. }\end{array}$ & $\begin{array}{l}\text { POT } \\
\text { EOT } \\
\text { POMCA }\end{array}$ & $\begin{array}{l}\text { No, de instrumentos de } \\
\text { ordenamiento del } \\
\text { territorio actualizados con } \\
\text { variables climáticas / No, } \\
\text { Total de instrumentos de } \\
\text { ordenamiento del } \\
\text { territorio. }\end{array}$ & $\begin{array}{l}\text { Nivel de } \\
\text { confiabilidad y } \\
\text { veracidad de los } \\
\text { instrumentos de } \\
\text { ordenamiento del } \\
\text { territorio. }\end{array}$ \\
\hline
\end{tabular}




\begin{tabular}{|c|c|c|c|c|}
\hline $\begin{array}{l}\text { Línea } \\
\text { de }\end{array}$ & Población Objetivo & Instrumentos & Indicador & Resultado \\
\hline \multirow{8}{*}{ 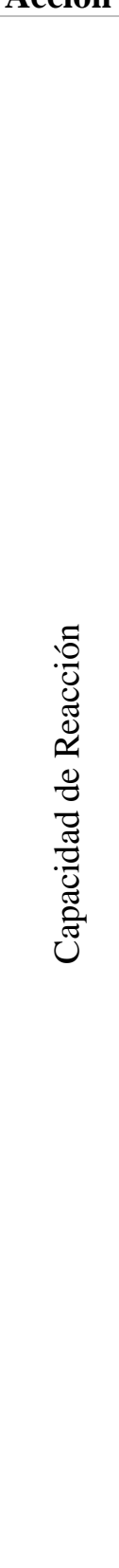 } & \multirow{8}{*}{$\begin{array}{l}\text { Comunidad de } \\
\text { agricultores cultivos } \\
\text { transitorios en la } \\
\text { región del Alto } \\
\text { Magdalena. } \\
\text { Entes territoriales y } \\
\text { entidades de control } \\
\text { de la región del Alto } \\
\text { Magdalena. }\end{array}$} & $\begin{array}{l}\text { Sistemas de } \\
\text { abastecimiento y drenaje } \\
\text { de agua. }\end{array}$ & $\begin{array}{l}\text { (No, de agricultores con } \\
\text { sistemas de } \\
\text { abastecimiento/ No, total } \\
\text { de agricultores) }\end{array}$ & \multirow{8}{*}{$\begin{array}{l}\text { Comunidades con } \\
\text { capacidad de } \\
\text { reacción ante los } \\
\text { cambios de las } \\
\text { variables } \\
\text { climáticas. }\end{array}$} \\
\hline & & Técnicas de cultivos. & $\begin{array}{l}\text { No, de agricultores que } \\
\text { ejecutan las técnicas de } \\
\text { cultivos apropiadas para } \\
\text { los cambios de las } \\
\text { variables climáticas / No, } \\
\text { total de agricultores. }\end{array}$ & \\
\hline & & $\begin{array}{l}\text { Aprovechamiento de los } \\
\text { nutrientes del suelo. }\end{array}$ & $\begin{array}{l}\text { No. de agricultores que } \\
\text { aprovechan los nutrientes } \\
\text { del suelo/ \# total de } \\
\text { agricultores }\end{array}$ & \\
\hline & & $\begin{array}{l}\text { Sistema de información } \\
\text { para la rotación de } \\
\text { cultivos. }\end{array}$ & $\begin{array}{l}\text { No, de agricultores que } \\
\text { consultan y ejecutan el } \\
\text { sistema de información } \\
\text { para rotación de cultivos / } \\
\text { No, total de agricultores. }\end{array}$ & \\
\hline & & $\begin{array}{l}\text { Mejoramiento genético } \\
\text { de las semillas para las } \\
\text { variables climáticas. }\end{array}$ & $\begin{array}{l}\text { No, de agricultores que } \\
\text { utilizan semilla mejorada } \\
\text { genéticamente/ No, total } \\
\text { de agricultores. }\end{array}$ & \\
\hline & & $\begin{array}{l}\text { Sistemas de reacción para } \\
\text { el control de plagas. }\end{array}$ & $\begin{array}{l}\text { No. de agricultores que } \\
\text { utilizan sistemas de } \\
\text { reacción de plagas/ No, } \\
\text { total de agricultores. }\end{array}$ & \\
\hline & & $\begin{array}{l}\text { Control de competencia } \\
\text { por agua, energía y } \\
\text { nutrientes. }\end{array}$ & $\begin{array}{l}\text { No, de agricultores que } \\
\text { utilizan técnicas de } \\
\text { aprovechamientos de } \\
\text { agua, energía y } \\
\text { nutrientes/ No, total de } \\
\text { agricultores. }\end{array}$ & \\
\hline & & $\begin{array}{l}\text { Implementación de } \\
\text { tecnologías limpias. }\end{array}$ & $\begin{array}{l}\text { No. de agricultores que } \\
\text { implementación de } \\
\text { tecnologías/ No, total de } \\
\text { agricultores. }\end{array}$ & \\
\hline
\end{tabular}

Fuente: Autora. 2015. 


\section{Conclusiones y Recomendaciones}

La producción de cultivos transitorios en la provincia del Alto Magdalena, ha tenido diferentes roles a lo largo del periodo analizado en los primeros años jugo un papel fundamental en el suministro de alimentos y materias primas para la agroindustria de concentrados. Sin embargo los ciclos de producción fueron cambiando y la vocación de la provincia fue transformándose hacia la prestación de servicios turísticos

La poca incorporación de tecnología e innovación en los sistemas de producción conjugaron un escenario vulnerable para los agricultores de los cultivos transitorios en la provincia; evidenciándose el efecto que tienen las variables climáticas en la producción agrícola en la región del Alto Magdalena. Una forma de reducir este impacto negativo es adaptar a la agricultura regional a las condiciones anómalas que recurrentemente imponen estas fases extremas.

Con esta investigación se pudo establecer que existe una relación directa entre la variable climática precipitaciones y la producción de cultivos transitorios en la provincia del Alto Magdalena en el departamento de Cundinamarca, lo cual expone a los agricultores a las variaciones del cambio climático convirtiéndolo en un sector bastante susceptible a estas variables exógenas.

La producción del cultivo de maíz es elástico frente a la variable climática precipitaciones al variar en un $1 \%$, la producción de este cultivo varía en 58,9\% los demás cultivos transitorios también se ven afectados en una menor medida, sorgo 6,4\%, arroz riego 11,96 \% y algodón con $4,2 \%$ 
Los agricultores de cultivos transitorios requieren de recompensas económicas que incentiven su producción, como líneas de crédito especiales para atender a las poblaciones que se ven afectadas por los fenómenos climáticos, seguros de acuerdo a las características productivas entre otras alternativas de mitigación

La estrategia planteada es coherente con lo propuesto por el Plan Nacional de Adaptación al Cambio Climático. Está encaminada a concientizar a la comunidad de agricultores en la potencial vulnerabilidad existente frente a los cambios de las variables climáticas; igualmente, en la generación de sistemas de información temprana para la modelación del riesgo, que permita formar la capacidad de reacción, con el uso de técnicas y tecnologías limpias para disminuir el impacto de los fenómenos climáticos.

De acuerdo con lo expuesto anteriormente, resulta importante que dentro de la estrategia de adaptación al cambio climático se realice una fuerte sensibilización a los agricultores. Así mismo, el suministro de la información requerida de sus cosechas al sistema de información, para que los entes territoriales tengan información veraz y completa, a fin asignar recursos para asumir la adaptabilidad al cambio.

En el desarrollo de este trabajo, se detectó ausencia de información, para la estimación del modelo; pues los datos de producción, área cosechada, área sembrada y rendimiento de los cultivos transitorios, son suministrados por el Sistema de Información Agronet, pero este no dispone del histórico del periodo de 1992-2006, lo que se tradujo en el levantamiento de información, en fuentes secundarias para este histórico.

La falta de adaptación de los agricultores de cultivos transitorios ante cambio climático, ha hecho que el reciente fenómeno del niño tenga un impacto negativo en sus rendimientos como se evidencio en el documento generando una caída en la productividad aumentando los precios, pues cultivos el maíz y el arroz, son cultivos básicos de la canasta familiar. 
El sector agrícola juega un papel importante como proveedor de alimentos y generador de materias primas para el sector industrial, siendo este estratégico para avanzar en el crecimiento económico, lo que nos lleva a pensar que los cultivos transitorios producidos en el Alto Magdalena tienen un fuerte potencial como proveedor de materias primas para la elaboración de biocombustibles con el fin de satisfacer la demanda energética que se está viviendo actualmente, bien sea con la utilización de subproducto como la cascarilla de arroz o con la producción o con la comercialización del cultivo directamente.

Para lograr desarrollar el potencial de los cultivos transitorios en producción de biocombustibles es importante generar un ambiente de cooperación y comunicación entre las instituciones que hacen parte del sector agrícola, he incentivado la investigación en la utilización de materias primas, en otros escenarios diferentes a alimentación humana o animal, para la generación de cadenas productivas.

Las pérdidas potenciales por las variaciones climáticas en los agricultores, se podrían reducir con la aplicación de medidas de adaptación como la utilización de tecnologías para el uso eficiente del agua, como sistema por goteo e implementar campañas para la conservación y manejo de suelos.

Desde el punto de vista del sector público es importante la inversión en infraestructura que le permitan a los agricultores más pobres, ser menos vulnerables frente a la disminución del régimen de lluvias, como la creación de un distrito de riego, que hasta el momento en la provincia del Alto Magdalena, no se cuenta con este sistema.

Finalmente extender los estudios expuestos en esta tesis, al estudio de otros tipos de cultivos, como lo son los cultivos permanentes, para tener un panorama total del sector agrícola de la Provincia del Alto Magdalena 


\section{Bibliografía}

Adams, R. M., Chen , C.-C., \& McCarl Bruce, R. F. (Diciembre de 1999). The economic consequences of ENOS events for agriculture. Climate Reseaech, 13, 165-172.

Albarrán Pérez, P. (2010). Universidad de Alicante. Recuperado el 15 de noviembre de 2014, de Repositorio Institucional: http://rua.ua.es/dspace/bitstream/10045/15809/6/Tema6p.pdf

Andrade Castañeda, H. J., Segura Madrigal, M. A., Canal , D. D., Gómez Martiínez, M. J., Marin Quintero, M., Guependo Ortiz, I. G., \& Feria Morales, M. (2013). Estrategias de adaptación al cambio climático en sistemas de producción agrícola y forestal en el departamento del Tolima. Ibagué, Colombia: Universidad del Tolima.

Alfonso, O., \& Alonso, C. (2012). Estudio sobre los efectos de la variabilidad climática sobre la dimensión de la disponibilidad dealimentos en la seguridad alimentaria en colombia e iniciativas de política. Recuperado el enero de 2016, de https://colaboracion.dnp.gov.co/CDT/Ambiente/Resumen\%20Ejecutivo\%20Final\%20Pag $\% 20$ indiv.pdf

Arellano, M. (1990). La econometría de datos de panel. Investigaciones Económicas (Segunda época), XIV(1), 3-45.

Arellano, M. (1992). Introducción al análisis económetrico con datos panel. Banco de España. Recuperado el 16 de noviembre de 2014, de http://www.bde.es/f/webbde/SES/Secciones/Publicaciones/PublicacionesSeriadas/Docum entosTrabajo/92/Fich/dt_9222.pdf

Bonilla, A., Rosales, R., \& Maldonado, J. (Septiembre de 2003). El valor económico de la predicción del fenómeno, El Niño del Sur (ENOS) en el sector azucareo colombiano. Desarrollo y Sociedad, 1-32.

Bonilla-Castro, E., \& Rodríguez Sehk, P. (1997). La investigación en ciencias sociales. Santafé de Bogotá, D.C.: Grupo Editorial Norma.

Brescia, V., Lema, D., \& Parellada, G. (Septiembre de 1998). El fenómeno ENSO y la agricultura pampena: Impactos económicos en trigo, maiz, girasol y soja. Argentina.

Campuzano, D. L. (2005). Plan nacional de investigación, desarrollo y fomento del cultivo de maiz tecnificado (2006-20020). Villavicencio: Corpoica.

Cardenas, A., Gil, H., \& Mejia , J. (2009). El comportamiento del sector agropecuario y su impacto sobre las economías departamentales: Una comperación naciona. Colombia. Obtenido de http://ribuc.ucp.edu.co:8080/jspui/bitstream/handle/10785/373/completo.pdf?sequence=1

Conde, C., Ferrer, R. M., Araujo , R., Gay, C., Magaña, V., Pérez, J., . . Orozco, S. (2004). Los impactos de el Niño en México. En V. MAGAÑA RUEDA (Ed.), El Niño y la agricultura (págs. 103-136). México.

DANE (Departamento Administrativo Nacional de Estad'sitica). (2007). Ficha Técnica Sistema de Información del Medio Ambiente. Obtenido de DANE. :

https://www.dane.gov.co/files/investigaciones/pib/ambientales/Sima/Cobertura_agricola.p df

DANE. (2007). Departamento Administrativo Nacional de Estadística (DANE). Obtenido de Investigaciones Ambientales Cobertura Agrícola: https://www.dane.gov.co/files/investigaciones/pib/ambientales/Sima/Cobertura_agricola.p df

Departamento Nacional de Planeación DNP. (2012). Plan Nacional de Adapatación al Cambio Climático. Contexto de la Planificación de la Adaptación al Cambio. Bogotá. 
Drukker, D. M. (24-25 de julio de 2008). Stata Data Analysis and Statistical Software.

Recuperado el 16 de novimebre de 2014, de Stata Conference and Users Group meetings: http://www.stata.com/meeting/snasug08/drukker_xtdpd.pdf

Enciclopedia Agropecuaria. (2001). INGENIERÍA Y AGROINDUSTRIA. Bogotá, D.C.: Terranova Editores, Ltda.

Field, B. C., \& Azqueta , D. (1996). Economía \& Medio Ambiente. Bogotá: McGraw-Hill.

FINAGRO. (N.F). Documentos Arroz. Obtenido de FINAgro Web Site: https://www.finagro.com.co/sites/default/files/node/info.../arroz.docx

Gobernación de Cundinamarca. (2006). Estadísticas Agropecuarias Volumen 20. Bogota.

Gobernación de Cundinamarca. (23 de 07 de 2015). Gobernación de Cundinamarca . Obtenido de Oficina Asesora de Planificación URPA:

http://www.cundinamarca.gov.co/wps/portal/Home/SecretariasEntidades.gc/Secretariadea gricultura/Secagriculturadespliegue/asplanificacionurpa_contenidos/csecreagri_planificac ionurpa

Gonzalez, J., \& Velasco, R. (2007). Evaluación del Impacto del Cambio Climático sobre el Valor Económico del Suelo en los Sistemas Agrícolas de Chile. Instituto de Investigaciones Agropecuarias, 1-3.

Jury, M. R. (2002). Economic Impacts of Climate Variability in South Africa and Development of. Journal of Applied Meteorology, 41, 46-51.

Labra, R., \& Torrecilla, C. (2014). Guia CERO para datos de panel. Un efoque práctico. UAMAccenture Working Papers. Cátedra UAM-Accenture en Economía y Gestión de la Innovación. Obtenido de https://www.uam.es/docencia/degin/catedra/documentos/16_Guia\%20CERO\%20para\%2 0datos\%20de\%20panel_Un\%20enfoque\%20practico.pdf

Lau, C., Jarvis, A., \& Ramirez , J. (2011). Agricultura Colombiana: Adaptación al Cambio Climático . CIAT Politícas en Síntesis (1), 4.

Mahía, R. (Marzo de 2000). Introducción a la especificación y estimación de modelos con datos de panel. España: Universidad Autónoma de Madrid. Obtenido de http://www.uam.es/personal_pdi/economicas/fphernan/EconometriaTVIII.pdf

Mayorga, M., \& Muñoz, E. (Septiembre de 2000). La técnica de datos de panel una guía para su e interpretación. (D. E.-D. ecómicas, Ed.) Costa Rica: Banco Central de Costa Rica.

Recuperado el 16 de octubre de 2014, de http://www.bccr.fi.cr/investigacioneseconomicas/metodoscuantitativos/Tecnica_datos_pa nel,_una_guia_para_su_uso_e_interpretacion.pdf

Mendez, Á. C. (2011). Metodología. Diseño y desarrollo del proceso de investigación con énfasis en ciencias empresariales. Limusa (Noriega Editores).

Méndez Arteaga, J., Duran Pinilla, L., Sandoval Aldana, A. P., Rivera, B. C., Torres Peñuela, A. M., Bernal Ruiz , M. R., \& González Rubio, J. (2011). Agenda propsectiva de investigación y desarrollo científico y tecnológico de la cadena porductiva del arroz en el departamento del Tolima 2010-2025. (C. C. Corpoica, Ed.) Ibagué, Colombia: Universidad del Tolima.

Miniesterio de Agricultura y Desarrollo Rural. (2013). Anuario estadístico del sector agropecuaio 2012. Bogotá: Dirección de Política Sectorial -Grupo de Sistemas de Información.

Miniesterio de Agricultura y Desarrollo Rural. (s.f.). Agronet. Recuperado el 10 de julio de 2014, de Agronet-Estadística:

http://www.agronet.gov.co/agronetweb1/Estad\%C3\%ADsticas.aspx 
Miniesterio de Educación. Gobierno de España. (s.f.). Instituto de Tecnologías Educativas. Recuperado el 15 de octubre de 2014, de Patrones de Variablidad Climática Índices de Circulación :

http://fjferrer.webs.ull.es/Apuntes3/Leccion05/1_el_fenmeno_de_la_oscilacin_del_surel_ nio_enso.html

Ministerio de Agricultura y Desarrollo Rural. (Octubre de 2012). Plan de mitigación de los efectos del Fenómeno El Niño en el sector agropecuario, acuícola y pesquero". Bogotá D.C, Colombia.

Ministerio de Agricultura y Desarrollo. (2014). Evaluaciones Agropecuarias Municipales 2013. Bogotá, Colombia.

Mora, J., Ramirez, D., Ordaz, J., Acosta , A., \& Serna, B. (Agosto de 2010). Panáma Efectos del Cambio Climático sobre la Agricultura. Recuperado el mayo de 2015, de Comisión Económica para América Latina y el Caribe CEPAL: http://repositorio.cepal.org/bitstream/handle/11362/25926/lcmex1971.pdf;jsessionid=9B1 D8D392EE658FDDB3A711E51D4ECF6? sequence $=1$

National Weather Service Climate Prediction Center. (s.f.). Recuperado el 4 de noviembre de 2014, de El Niño/ Southern Oscillation (ENSO): http://www.cpc.noaa.gov/products/analysis_monitoring/ensostuff/ensoyears.shtml

Oliviera, S. (Marzo de 2013). La productividad del maiz de temporal en México: repercusiones del cambio climático. Obtenido de Comisión Económicas para América Latina y el Caribe CEPAL.

Ortiz, R. (febrero de 2012). El cambio climático y la prodrucción agrícola . Notas Técnicas- . Banco Interamerciano de Desarrollo .

Penagos, C. G. (2014). Variables hidrometereológicas asociadas al cambio climático en Girardot y la Región del Alto Magdalena. Ambiente y Desarrollo. Universidad Javeriana, 133-47. doi:10.11144/Javeriana.AyD18-35.vhac

Ramirez, D., Ordaz, J., \& Mora, J. (12 de noveimbre de 2009). ISTMO Centroamericano: Efectos de cambio Climático sobre la Agricultura. Obtenido de Comisión Económica para América Latina y el Caribe CEPAL.: http://smye.info/gia-mexico/wpcontent/uploads/2010/07/L924_Parte_1.pdf

Redacción Vivir. (25 de abril de 2014). Fénomeno del Niño llegará en julio. El Espectador. Recuperado el 16 de noviembre de 2014, de http://www.elespectador.com/noticias/medioambiente/fenomeno-del-nino-llegara-julio-articulo-488793

Revista Dinero. (3 de marzo de 2015). Bajará el consumo de arroz en Colombia durante 2015. Revista Dinero. Obtenido de http://www.dinero.com/pais/articulo/precios-del-arrozcolombia/206817

Rojas, R. (1999). Universidad de los Andes. Recuperado el 10 de julio de 2014, de web del profesor: http://webdelprofesor.ula.ve/ingenieria/rojas.r/evaepic2.pdf

Ruiz, C. (n.f de n.f). Instituto de Investigaciones Agropecuarias. Obtenido de Biblioteca: http://www2.inia.cl/medios/biblioteca/serieactas/NR29558.pdf

Ruiz Cabarcas, A. (2012). Análisis del impacto de los fenómenos El Niño y La Niña en la producción agrícola del departamento del Atlántico. Bogotá, Colombia.

Sarabia Alegría, J., \& Pascual Sáez, M. (2006). Estadística para economía y administración de empresas. Santander: Universidad de Cantabria. Recuperado el 38 de septiembre de 2014, de

http://books.google.com.co/books?id=QEp1dROP0OAC\&pg=PA134\&lpg=PA134\&dq=c oeficiente+de+correlacion+variables+binarias \&source=bl\&ots=UWFvd8ntTv\&sig=4huT 
8568aTVIBN-

sDDhBZ5zbzIA\&hl=en\&sa=X\&ei=ahRqVMz_IMeYgwSF04OICg\&ved=0CDoQ6AEw

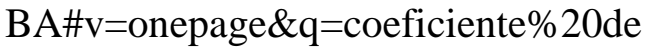

Sloman, J. (1997). Introducción a la Microeconomía. Madrid: Prentice Hall.

Stern, N. (2007). El Informe Stern, la verdad sobre el cambio climático. (A. Santos, \& J.

Vilatella, Trads.) Barcelona, España: Ediciones Paidós Ibérica S.A.

Universidad del Cema. (s.f.). Econometría Aplicada-UCEMA. Notas de clase 10 Modelos

Dinámicos para datos de panel. Argentina. Recuperado el 3 de noviembre de 2014,dehttp://www.ucema.edu.ar/u/dl/CURSOSAE/NOTAS_CLASE_10_PANEL_DINA MICO.pdf

Vargas, P. (Julio de 2009). Banco Central de la Reserva del Perú. Recuperado el Junio de 2015, de Publicaciones Documentos de Trabajo:

http://www.bcrp.gob.pe/docs/Publicaciones/Documentos-de-Trabajo/2009/Documentode-Trabajo-14-2009.pdf 
ANEXOS 


\section{ANEXO A}

Tabla 9 Estimación Efectos Fijos Cultivo Sorgo

xtreg LnProd LnAreaCosechad Ln_Precipitación, fe

\begin{tabular}{|c|c|c|}
\hline Fixed-effects (within) regression & Number of obs & 84 \\
\hline Group variable: ID & Number of groups $=$ & 6 \\
\hline R-sq: & Obs per group: & \\
\hline within $=0.9867$ & $\min =$ & 21 \\
\hline between $=0.9946$ & avg : & 21.0 \\
\hline overall $=0.9891$ & $\max :$ & \\
\hline & $F(2,78)$ & 2898 \\
\hline $\operatorname{corr}\left(u_{-} i, x b\right)=-0.4074$ & Prob $>F$ & 0.00 \\
\hline
\end{tabular}

\begin{tabular}{|c|c|c|c|c|c|c|}
\hline LnProd & Coef. & Std. Err. & t & $P>|t|$ & [95\% Conf & Interval] \\
\hline LnAreaCosechad & 1.141808 & .0151354 & 75.44 & 0.000 & 1.111676 & 1.17194 \\
\hline Ln_Precipitación & -.0405638 & .0217925 & -1.86 & 0.066 & -.0839493 & .0028218 \\
\hline _cons & .0259905 & .0750217 & 0.35 & 0.730 & -.1233663 & 1753473 \\
\hline sigma_u & 19956034 & & & & & \\
\hline sigma_e & .26821799 & & & & & \\
\hline rho & .35632131 & (fraction & of varia & ce du & u_i) & \\
\hline
\end{tabular}

F test that all $u_{-} \mathrm{i}_{-}=0: \mathrm{F}(3,78)=9.68 \quad$ Prob $>\mathrm{F}=0.0000$

Fuente Autora. 2015 


\section{ANEXO B}

Tabla 10 Estimación Efectos Aleatorios Cultivo Sorgo

xtreg LnProd LnAreaCosechad Ln_Precipitación, re

\begin{tabular}{|c|c|c|}
\hline Random-effects GLS regression & Number of obs & 84 \\
\hline Group variable: ID & Number of groups & 4 \\
\hline R-sq: & Obs per group: & \\
\hline within $=0.9867$ & $\min =$ & 2 \\
\hline between $=0.9946$ & avg $=$ & 21.0 \\
\hline overall $=0.9891$ & $\max =$ & 21 \\
\hline & Wald chi2(2) & 7353.83 \\
\hline $\operatorname{corr}\left(u_{-} i, x\right)=\theta$ (assumed) & Prob > chi2 & 0.0000 \\
\hline
\end{tabular}

\begin{tabular}{|c|c|c|c|c|c|c|}
\hline LnProd & Coef. & Std. Err. & $z$ & $P>|z|$ & {$[95 \%$ Conf } & Interval] \\
\hline LnAreaCosechad & 1.114282 & .0131349 & 84.83 & 0.000 & 1.088538 & 1.140026 \\
\hline Ln_Precipitación & -.0439144 & .0250409 & -1.75 & 0.079 & -.0929937 & .005165 \\
\hline _cons & 1498525 & .0689221 & 2.17 & 0.030 & .0147676 & .2849374 \\
\hline sigma_u & $\theta$ & & & & & \\
\hline sigma_e & .26821799 & & & & & \\
\hline rho & $\theta$ & (fracti & var & ice $d t$ & $u_{-}$i) & \\
\hline
\end{tabular}

Fuente Autora. 2015 


\section{ANEXO C}

Tabla 11 Test de Hauman Cultivo de Sorgo.

hausman FE RE

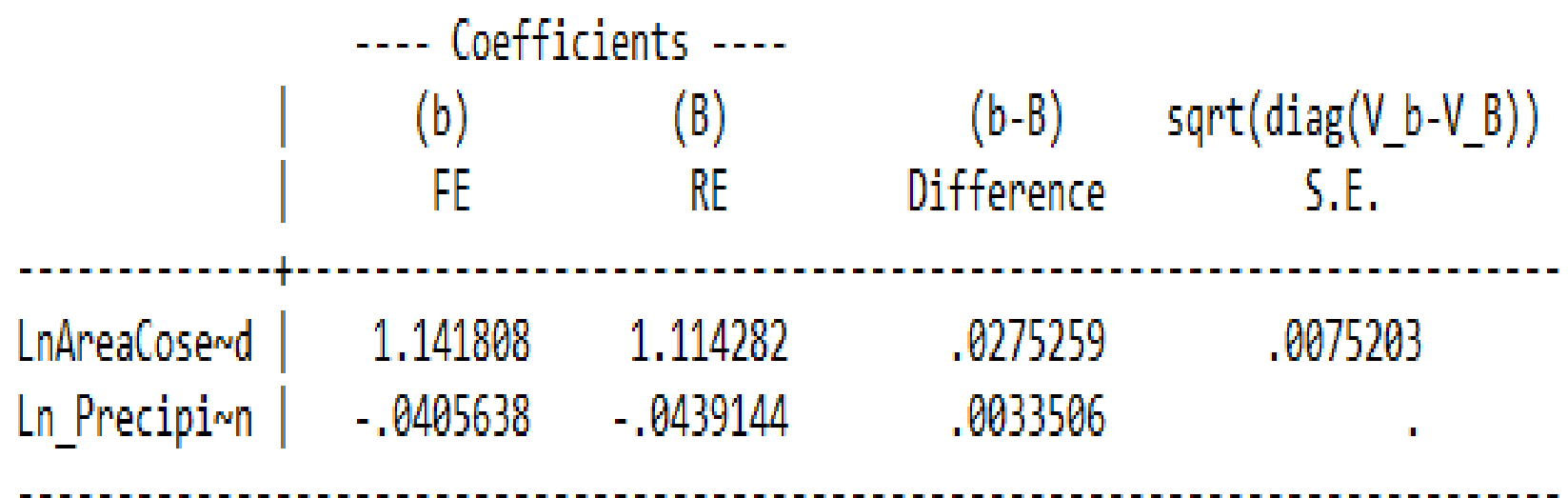

$$
\begin{aligned}
& b=\text { consistent under } H_{0} \text { and } H_{a} \text {; obtained from xtreg } \\
& B=\text { inconsistent under } H_{a} \text {, efficient under } H_{0} \text {; obtained from xtreg }
\end{aligned}
$$

Test: Ho: difference in coefficients not systematic

$$
\begin{aligned}
\text { chi2 }(2) & =(b-B)^{\prime}\left[\left(V_{-} b-V_{-} B\right)^{A}(-1)\right](b-B) \\
& =13.18 \\
\text { Prob }>c h i 2 & =0.0014 \\
\text { (V_b-V_B } & \text { is not positive definite })
\end{aligned}
$$

Fuente Autora. 2015 


\section{ANEXO D}

Tabla 12 Estimación Arroz Riego Efectos Fijos

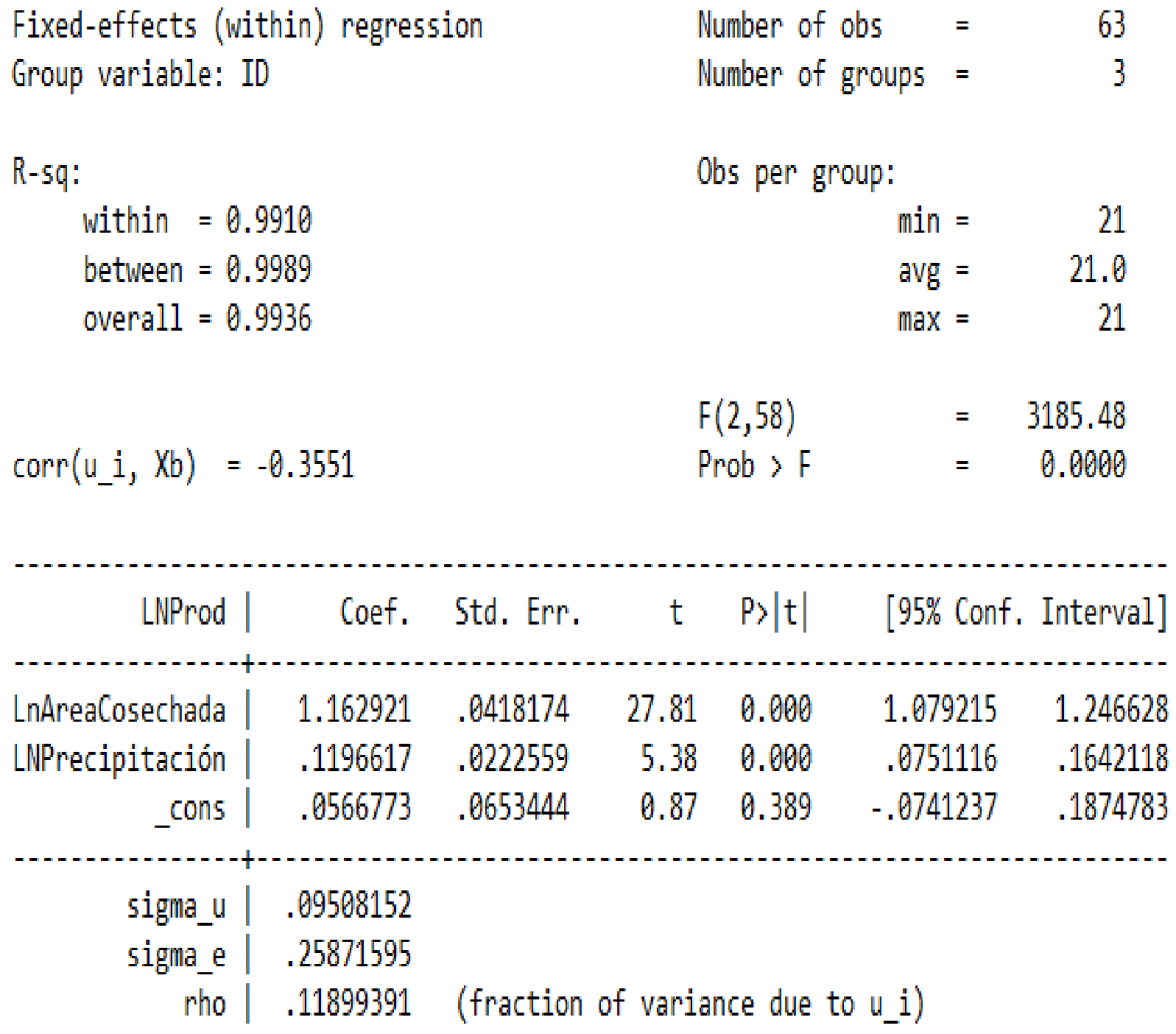

$F$ test that all $u_{-} i_{0}=0: F(2,58)=2.12 \quad$ Prob $>F=0.0000$

Fuente Autora. 2015 


\section{ANEXO E}

Tabla 13 Estimación Efectos Aleatorios Cultivo de Arroz de Riego

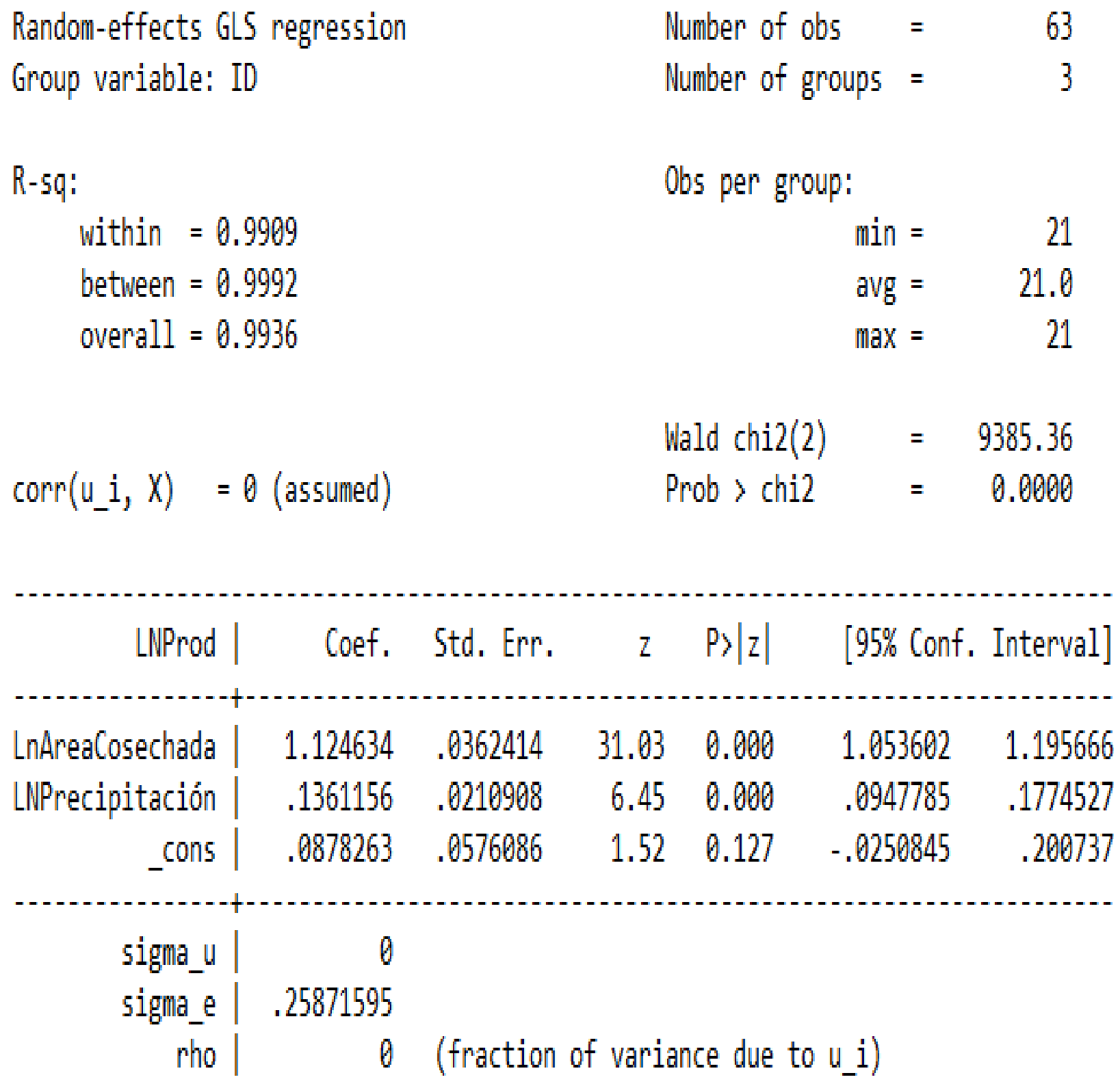

Fuente Autora. 2015 


\section{ANEXO F}

Tabla 14 Test de Hausman. Cultivo de Arroz de Riego

- hausman fe re

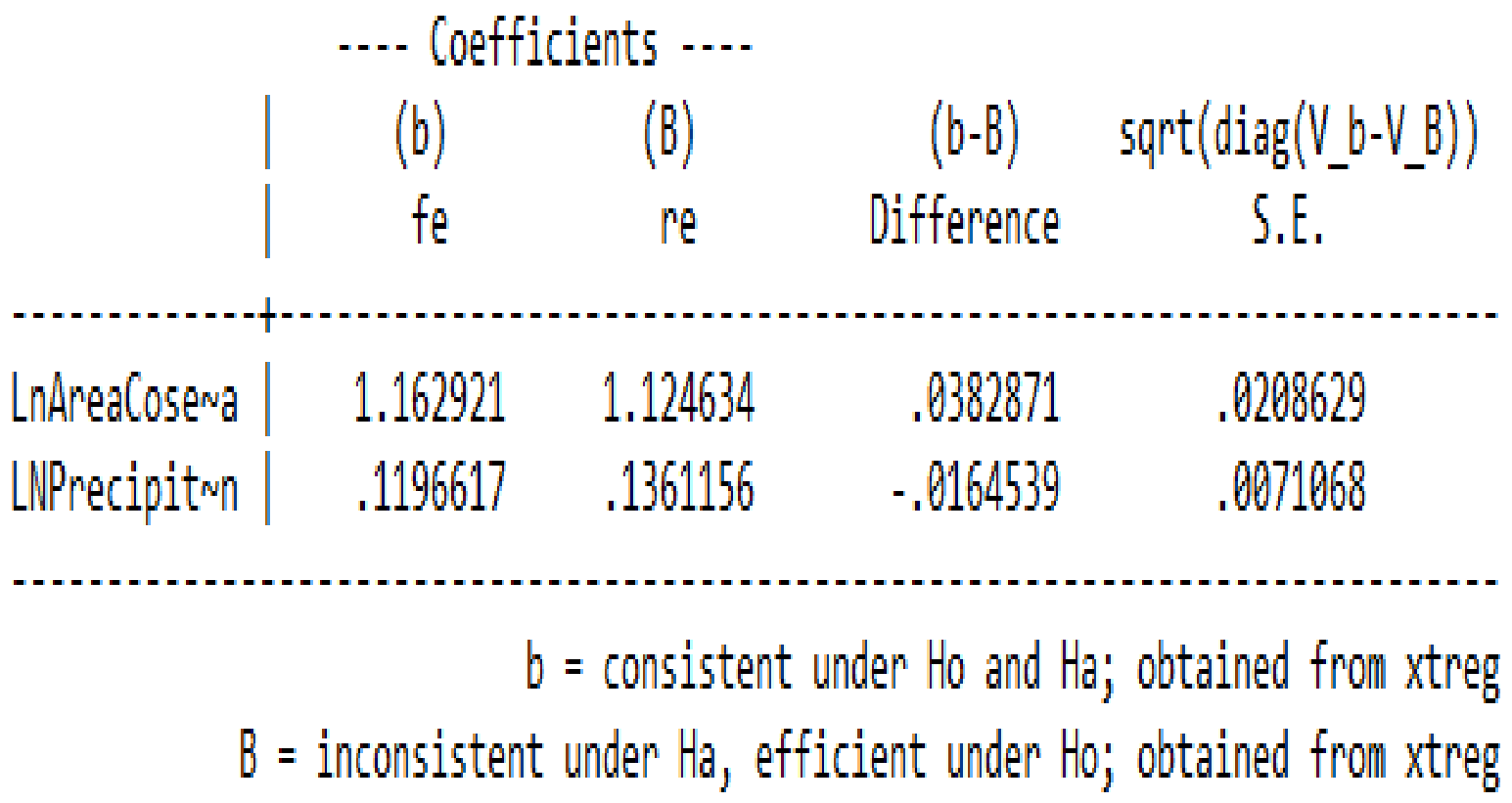

Test: Ho: difference in coefficients not systematic

$$
\begin{aligned}
\operatorname{chi} 2(2) & =(b-B)^{\prime}\left[\left(V_{-} b-V \_B\right)^{N}(-1)\right](b-B) \\
& =7.30 \\
\text { Probychi2 } & =0.0260
\end{aligned}
$$

Fuente Autora. 2015 


\section{ANEXO G}

Tabla 15 Estimación Efectos Fijo Cultivo de Algodón

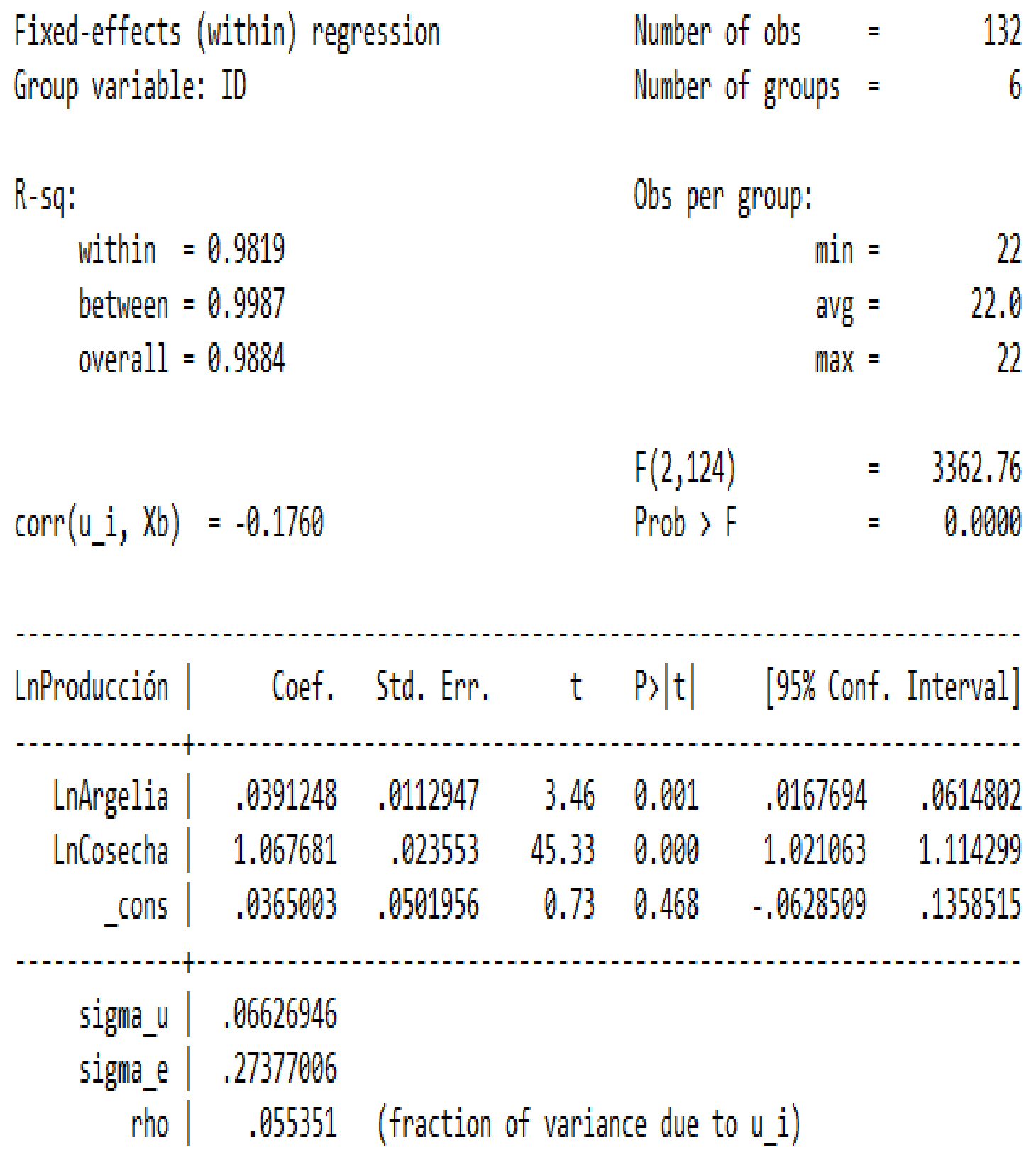

$F$ test that all $u_{-} \mathrm{i}=0: \mathrm{F}(5,124)=1.20 \quad$ Prob $>F=0.3151$

Fuente Autora. 2015 


\section{ANEXO H}

Tabla 16 . Estimación Efectos Aleatorios Cultivo de Algodón

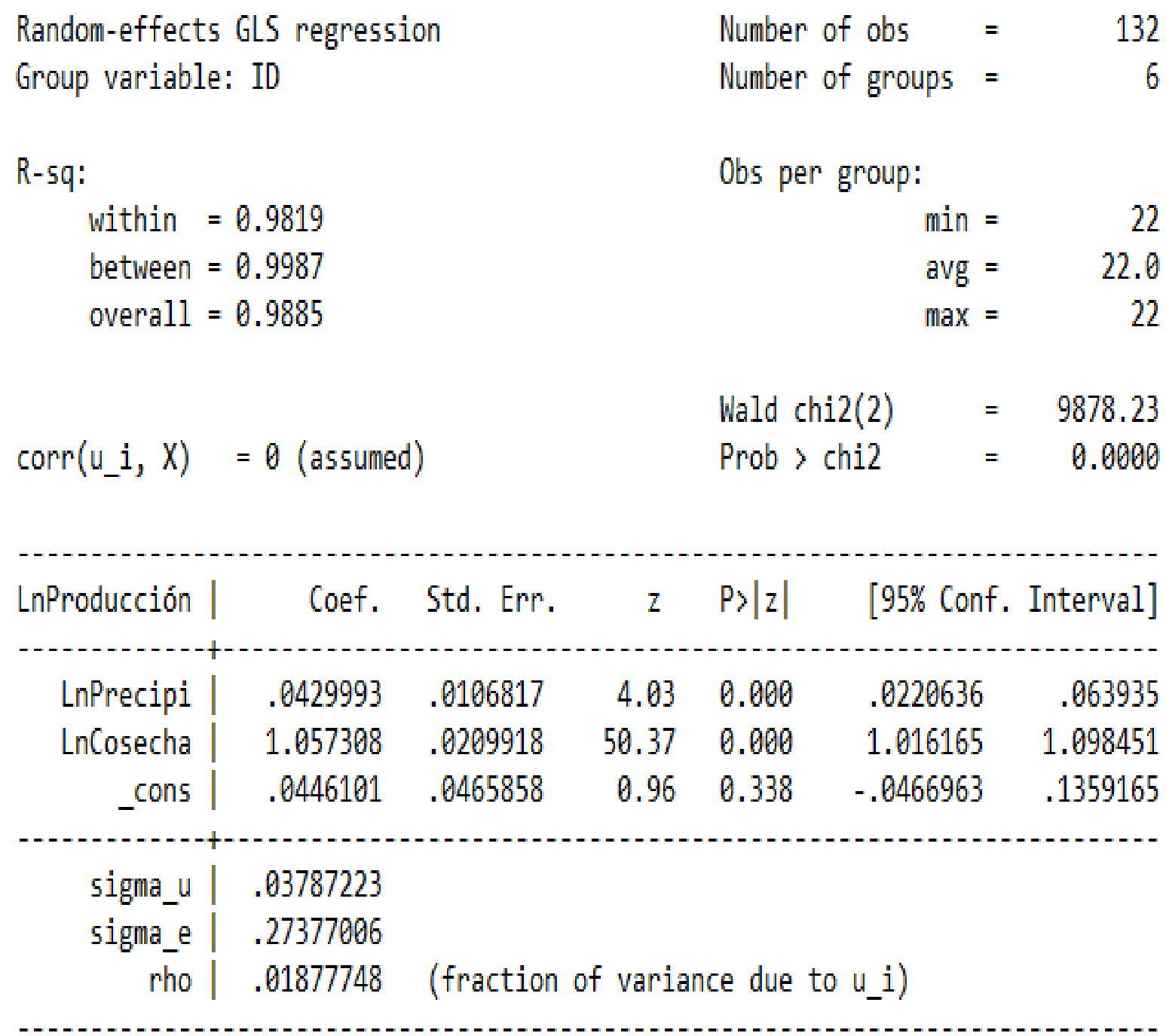

Fuente: Autora. 2015 


\section{ANEXO I}

Tabla 17 Test de Hauman. Cultivo de Algodón

Figura 187. Test de Hauman. Cultivo de Algodón

- hausman fe re

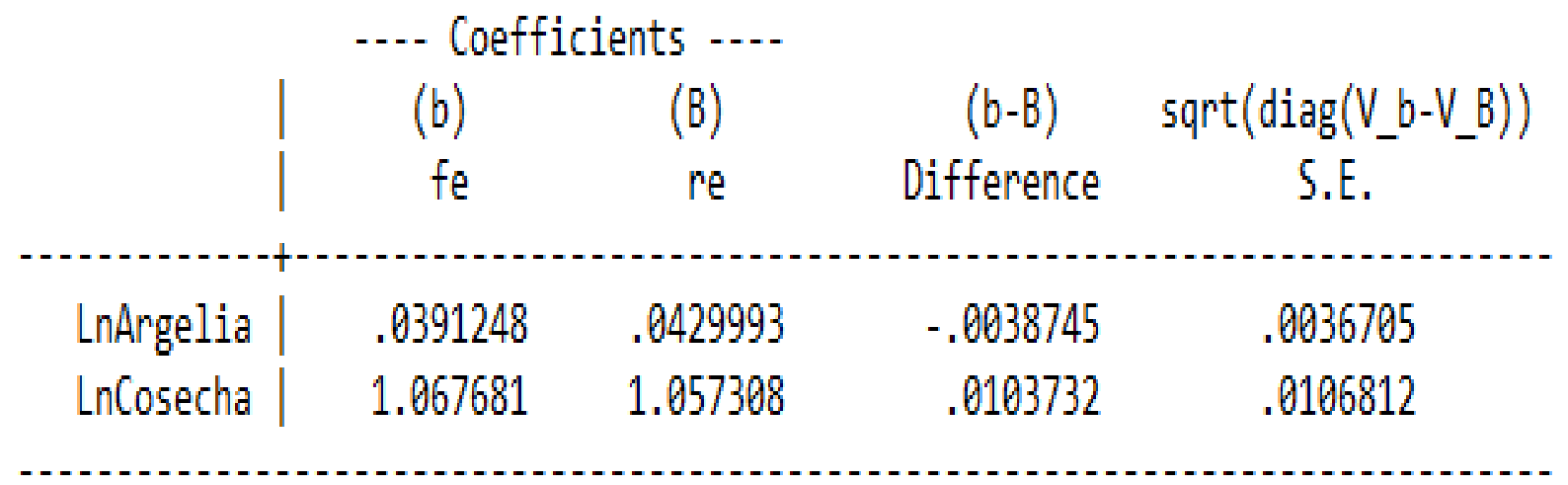

$b=$ consistent under Ho and Ha; obtained from xtreg $B=$ inconsistent under $\mathrm{Ha}$, efficient under $\mathrm{Ho}_{0}$; obtained from xtreg

Test: Ho: difference in coefficients not systematic

$$
\begin{aligned}
\text { chi2 }(2) & = & (b-B)^{\prime}\left[\left(V_{-} b-V_{-} B\right)^{N}(-1)\right](b-B) \\
& = & 1.23 \\
\text { Probschi2 } & = & 0.5400
\end{aligned}
$$

Fuente Autora. 2015 